PNL-3949

UC-70

\title{
An Analysis of the Cost of Mined Geologic Repositories in Alternative Media
}

\author{
L. L. Clark \\ B. M. Cole
}

February 1982

Prepared for the U.S. Department of Energy under Contract DE-AC06-76RLO 1830

Pacific Northwest Laboratory

Operated for the U.S. Department of Energy by Battelle Memorial Institute 


\title{
DISCLAIMER
}

This report was prepared as an account of work sponsored by an agency of the United States Government. Neither the United States Government nor any agency thereof, nor any of their employees, makes any warranty, express or implied, or assumes any legal liability or responsibility for the accuracy, completeness, or usefulness of any information, apparatus, product, or process disclosed, or represents that its use would not infringe privately owned rights. Reference herein to any specific commercial product, process, or service by trade name, trademark, manufacturer, or otherwise, does not necessarily constitute or imply its endorsement, recommendation, or favoring by the United States Government or any agency thereof. The views and opinions of authors expressed herein do not necessarily state or reflect those of the United States Government or any agency thereof.

\author{
PACIFIC NORTHWEST LABORATORY \\ operated by \\ BATTELLE \\ for the \\ UNITED STATES DEPARTMENT OF ENERGY \\ under Contract DE-AC06-76RLO 1830
}

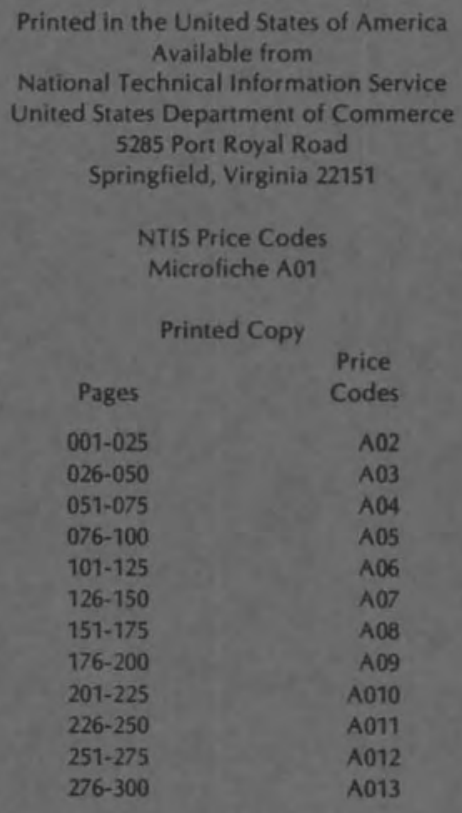


PNL -3949

UC -70

AN ANALYSIS OF THE COST OF MINED GEOLOGIC REPOSITORIES IN ALTERNATIVE MEDIA
L. L. C1 ark
B. M. Cole

February 1982

Prepared for

U.S. Department of Energy under Contract DE-AC06-76RLO 1830

Pac if ic Northwest Laboratory

Richland, Washington 99352 
In 1981 the Office of Nuclear Waste Isolation (ONWI) commissioned the Pac if ic Northwest Laboratory ( $P N L)$ to prepare a consistent set of preliminary estimates of the costs associated with constructing and operating nuclear waste repositories for spent fuel in salt, basalt, granite and tuff. The study incorporated information available through June 1981 to determine the design parameters driving the costs, with emphasis on determining the sets of conditions most favorable for each medium from a cost viewpoint.

A computer model, designated RECON, was developed to facilitate the cost analysis. Data for the model were taken from recent conceptual repository design estimates and from the Generic Environmental Impact Statement on Commercial Radioactive Waste Management (GEIS) (DOE 1980a). Because the economics of nuc lear waste repositories are driven by many complex interacting factors, only a few of which could be included in the model, and because the quality of the input data varies substantially for the different media, the cost differences that appear among media must be considered cautiously. As better data become available, these differences may change.

The results of the analys is show that undiscounted total repository costs in 1981 dollars for a 2000-acre repository with a long-lived borehole package containing disassembled, close-packed spent fuel, range from $\$ 7.6$ billion in salt to $\sim \$ 9$ billion in granite. These costs include all construction, operating and decommissioning costs for receiving, packaging and isolating spent fue 1, contact-handled TRU wastes and assembly hardware wastes. Unit costs for these repositories range from $\$ 82$ to 107 per kilogram of heavy metal ( $\$ / \mathrm{kg} \mathrm{HM}$ ) in salt and basalt, respectively. Differences in repository costs are mainly due to media-specific costs of mining and drilling and different limiting thermal criteria.

A cost-sensitivity analysis of key repository design parameters indicates that package materials and package fuel density are the driving cost factors in spent fuel repository designs. For example, using a long-lived borehole package containing 1 intact pressurized water reactor (PWR) assembly or 2 intact boiling water reactor (BWR) assemblies would cost $\$ 66$ to $\$ 86 / \mathrm{kg} H M$, 
or $\$ 3$ to 5 billion in total cost, more than using a long-lived borehole package containing disassembled, close-packed fuel rods from 3 PWR or 8 BWR assemblies.

Other variables significantly affecting repository costs in order of sensitivity are package dimensions, hole barriers and emplacement designs, cost of money, limiting thermal criteria and repository size. Alternative emplacement designs and less restrictive themal loading for a 2000-acre repository result in additional unit cost reductions of $\$ 4 / \mathrm{kg} H M$ in salt and $\$ 8$ to $9 / \mathrm{kg}$ $H M$ in basalt and granite. 


\section{CONTENTS}

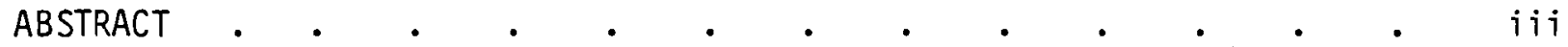

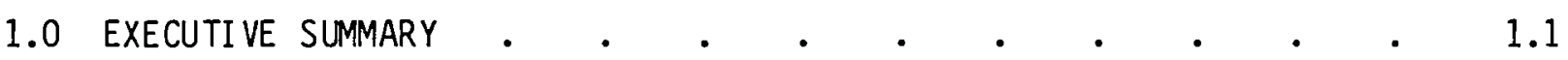

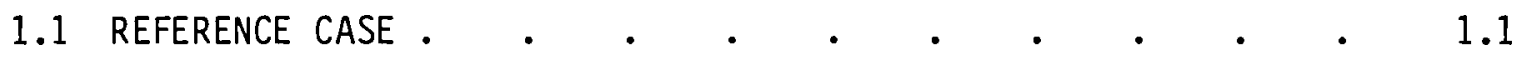

1.2 SENSITIVITY ANALYSIS RESULTS

2.0 INTRODUCTION

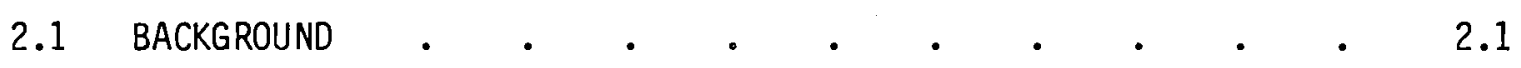

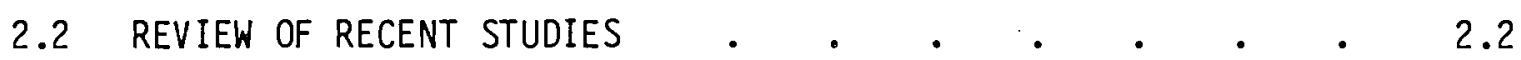

2.3 APPROACH . . . . . . . . . . . . . 2.3

3.0 THE RECON MODEL $\quad$ •

3.1 SURFACE OPERATIONS •

3.2 MINE DEVELOPMENT

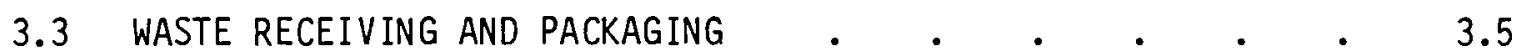

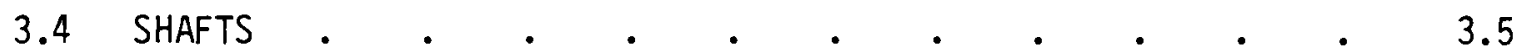

3.5 UNDERGROUND OPERATIONS

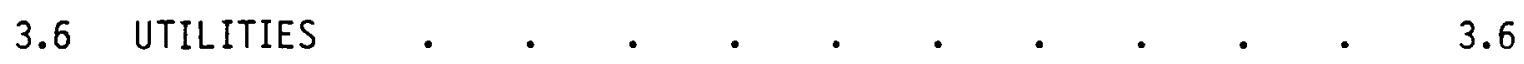

3.7 FACILITY, CONSTRUCTION AND EQUIPMENT COSTS . $. \quad . \quad . \quad 3.7$

3.8 PREPRODUCTION .

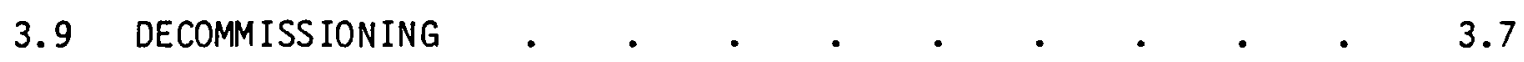

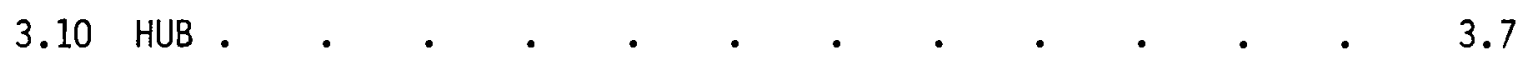

4.0 MODEL VERIFICATION WITH CONCEPTUAL REFERENCE REPOSITORY

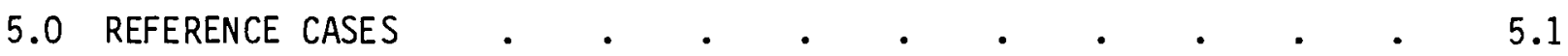

5.1 REFERENCE CASE DESCRIPTIONS 
5.2 DATA DESCRIPTION AND SOURCES •

5.2 .1 Facilities . . . . . . . . . . . 5.2

5.2 .2 Packaging . . . . . . . . . . . 5.3

5.2.3 Fuel Receipt Schedule . . . . . . . 5.5

5.2.4 Mining and Rock Handling . . . . . . . 5.5

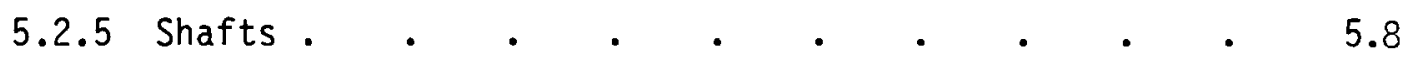

5.2.6 Underground Waste Operations . $\quad . \quad . \quad . \quad . \quad 5.9$

5.2.7 Emplacement Configurations . . . . . . 5.9

5.2.8 Other Reference Case Assumptions . . . . 5.11

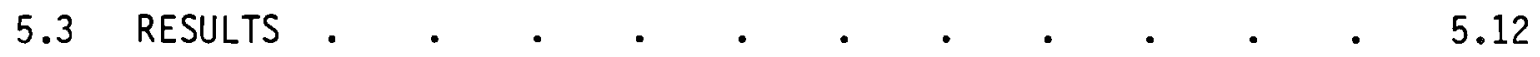

5.3.1 Total Costs . . . . . . . . . . 5.12

5.3 .2 Cash flow $. \quad . \quad . \quad . \quad . \quad . \quad . \quad . \quad . \quad .5 .16$

5.3 .3 Unit Costs . $. \quad . \quad . \quad . \quad . \quad . \quad . \quad . \quad .50$

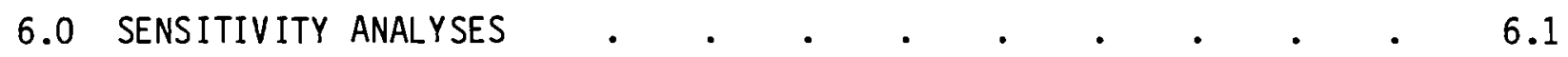

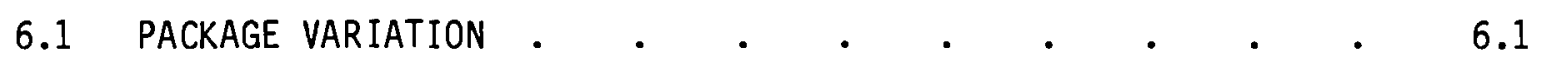

6.2 THERMALLY LIMITING VARIABLES . • . . . . . . . 6.3

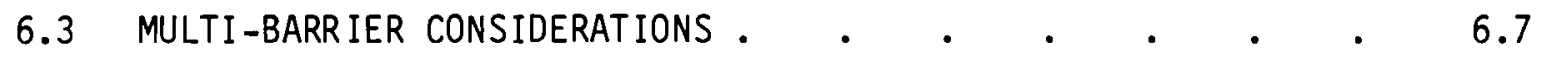

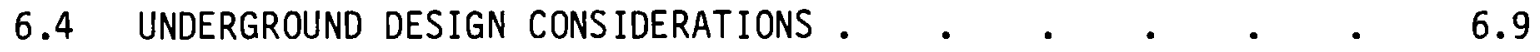

6.5 SELECTED OPERATING COST DATA SENSITIVITY $\cdot \cdots \cdot c \cdot c \cdot 6.14$

6.6 COST OF FUNDS .

6.7 COMBINED PARAMETRIC EFFECTS . . . . . . . . . $\quad .6 .18$

REFERENCES • •

APPENDIX A - BASALT REPOSITORY COST ESTIMATE USING BASALT

WASTE ISOLATION PROJECT DATA 
1.1 The Effect of Packaging Concept on Unit Repository Costs in Alternative Media. . . . . . . . . . . 1.5

3.1 RECON Cost Model Illustration . . . . . . . . 3.2

6.1 The Effect of Packaging Concept on Unit Repository Costs

6.2 The Effect of Minimum Hole Pitch . . . . . . . . 6.4

6.3 The Effect of Near-Field Thermal Loading on Unit

Repository Costs . . . . . . . . . . . . 6.5

6.4 The Effect of Bentonite Backfill Annular Radius on

6.5 The Effect of Package Diameter on Unit Costs . . . . . 6.9

6.6 The Effect of Package Length on Unit Costs . . . . . 6.10

6.7 The Effect of Extraction Ratio on Unit Repository Costs . . 6.11

6.8 The Effect of Number of Rows Per Room on Unit

6.9 The Effect of Repository Size on Unit Costs . . . . . 6.14

6.10 The Effect of Unit Mining and Rock Handling Costs on
Unit Repository Costs . . . . . 6.15

6.11 The Effect of Unit Hole Excavation Costs on Unit

6.12 The Effect of Cost of Money on Unit Costs . . . . . 6.17

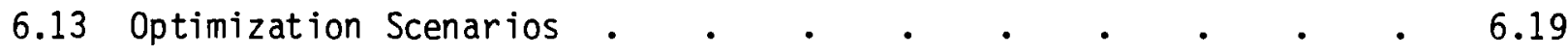

6.14 The Effect of Extraction Ratio on Repository Capacity
Using Four Rows Per Room . . . . . . . 6.20

6.15 The Effect of Extraction Ratio on Total Rock Mined
Using Four Rows Per Room . . . . . . . . 6.21

A.1 A Comparison of BWIP Repository Costs Versus the
Reference Basalt Case in this Study . . . . . . . A.4 


\section{$\underline{\text { TABLES }}$}

1.1 Total Cost Estimates for Generic Reference Repositories in

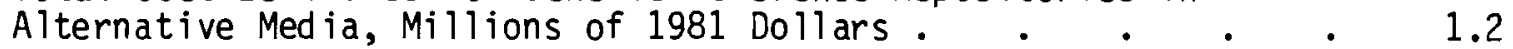

1.2 Data Summary for Generic Reference Repositories . $\quad$ • $\quad$ - 1.2

1.3 Unit Cost Estimates for Generic Reference Repositories in Alternative Media, $\$ / \mathrm{Kg} \mathrm{HM}$. $\quad . \quad . \quad . \quad . \quad . \quad . \quad . \quad 1.3$

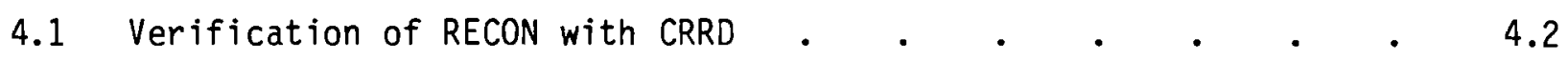

5.1 Spent Fuel Ten Years 01d or 01der, Available for Regional

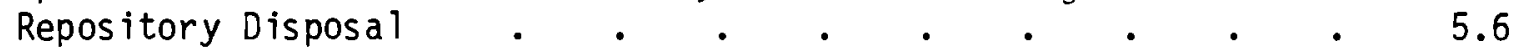

5.2 Escalation Factors Based on GNP Deflator $\quad . \quad$. $\quad . \quad$. $\quad . \quad 5.12$

5.3 Total Costs for Reference Repositories in Alternative Media, Millions of 1981 Dollars $. \quad . \quad . \quad . \quad . \quad . \quad . \quad . \quad 5.13$

5.4 Annual Receipts and Emplacement Area Requirements for Reference

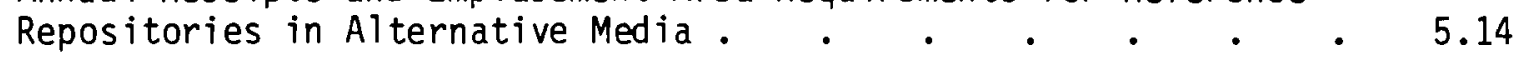

5.5 Center-To-Center Canister Spacing and Limiting Placement Criteria for the Reference Cases in Alternative Media . $\quad$. 5.15

5.6 Shaft Cost Estimates for the Reference Case, Millions of 1981 Dollars . $. \quad . \quad . \quad . \quad . \quad . \quad . \quad . \quad$. 5.17

5.7 Rock Logistics Surmary for Reference Cases, Millions

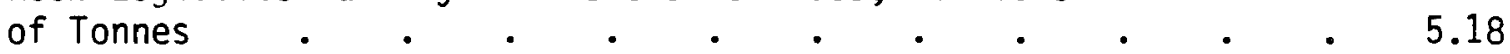

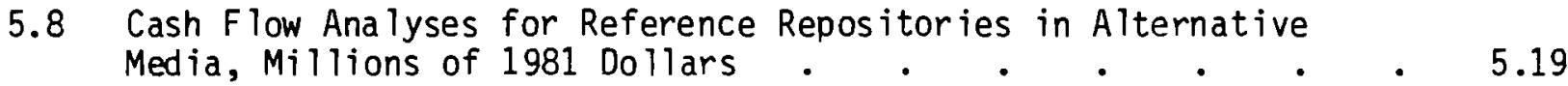

5.9 Unit Cost Sumary for Reference Repositories in
Alternative Media . . . . . . . . . 5.20

A.1 Cost Summary for BWIP Repository . . . . . . . . . A.3 


\subsection{EXECUTIVE SUMMARY}

In 1981, the Pacific Northwest Laboratory (PNL) conducted an analys is of the costs of using salt, granite, basalt or tuff to isolate spent nuclear fuel. Preliminary cost estimates were made and the conditions affecting cost in each medium were examined parametrically. The analysis was conducted using a repository cost model named RECON, created for this project. Data for the mode 1 were gathered from recent conceptual design studies completed and under way, from the Generic Environmental Impact Statement on Commercial Radioactive Waste Management (GEIS), and from reports on specific, related topics. These data were current through June 1981.

The study approach was to select reference repository descriptions and costs for each of the previously mentioned media. These descriptions were used as baselines to evaluate the cost sensitivity of key repository design parameters such as package design, thermal loading limits, additional radionuclide migration barriers, repository size, and emplacement design. The sensitivity of input cost parameters such as cost of money, mining, and hole drilling was also examined. Following the sensitivity analyses, the cost model was used to explore cost-effective alternative emplacement designs for the different media.

\subsection{REFERENCE CASE}

The construction, operating and decommissioning cost estimates for the generic reference cases are shown in Table 1.1. These estimates are for 2000acre repositories having the capacities and operating periods shown in Table 1.2. Total costs range from $\$ 7.6$ billion for a repository in salt to $\$ 9$ billion for one in granite, stated in undiscounted 1981 dollars. Operating costs account for $\sim 60 \%$ of total costs and are incurred over time periods ranging from 24 to 28 years. Costs were also examined for a basalt repository with the assumption of an approximately equivalent quantity of spent fuel as in the salt, granite and tuff repositories. These results are shown in the figures in parentheses in Table 1.1 and Table 1.2. Total costs of this option are about $\$ 9.4$ billion. 
TABLE 1.1. Tota 1 Cost Estimates for Generic Reference Repositories in Alternative Media, Millions of 1981 Dollars

\begin{tabular}{|c|c|c|c|c|}
\hline & Salt & Granite & Basalt (b) & $\underline{\text { Tuff }}$ \\
\hline Construction Costs & 1590 & 1670 & $1610(1770)$ & 1650 \\
\hline Operating Costs (a) & 4660 & 5680 & $4930(5940)$ & 5230 \\
\hline Decommissioning Costs & 120 & 140 & $140 \quad(140)$ & 130 \\
\hline Contingencies @ $20 \%$ & $\underline{1270}$ & 1500 & $\underline{1340}(1570)$ & $\underline{1400}$ \\
\hline TOTAL & 7640 & 8990 & $\overline{8020}(9420)$ & $\overline{8410}$ \\
\hline
\end{tabular}

(a) Includes mining costs during waste disposal operations.

(b) The figures in parentheses include costs if the basalt repository were expanded to dispose of an equivalent amount of spent fuel (see Table 1.2).

TABLE 1.2. Data Sumary for Generic Reference Repositories

\begin{tabular}{|c|c|c|c|c|c|}
\hline \multirow[b]{2}{*}{$\begin{array}{l}\text { Capac ity, Thousands of } \\
\text { Spent Fuel Assemblies }\end{array}$} & \multirow{2}{*}{$\begin{array}{l}\text { Salt } \\
309\end{array}$} & \multirow{2}{*}{$\begin{array}{l}\text { Granite } \\
304\end{array}$} & \multicolumn{2}{|c|}{ Basa 1t ${ }^{(a)}$} & \multirow{2}{*}{ Tuff } \\
\hline & & & 249 & (305) & \\
\hline Thousands of Packages (b) & 65 & 64 & 53 & $(65)$ & 64 \\
\hline $\begin{array}{l}\text { Total Rock Mined, } \\
\text { Millions of MT }\end{array}$ & 24 & 30 & 31 & $(37)$ & 26 \\
\hline $\begin{array}{l}\text { Near-Field Thermal } \\
\text { Loading, kW/Acre }\end{array}$ & 56 & 55 & 45 & $(45)$ & 55 \\
\hline $\begin{array}{l}\text { Period of Operation, } \\
\text { Years }\end{array}$ & 28 & 27 & 24 & $(27)$ & 27 \\
\hline \multicolumn{6}{|c|}{$\begin{array}{l}\text { (a) The figures in parentheses include equivalent data if the } \\
\text { basalt repository were expanded to hold } 305,000 \text { spent fue } 1 \\
\text { assemblies. } \\
\text { (b) Assuming } 3 \text { PWR or } 8 \text { BWR assemblies per package. }\end{array}$} \\
\hline
\end{tabular}

The basic repository designs for all media assume that titanium-clad carbon steel packages are emplaced in vertical holes containing a carbon steel sleeve surrounded by a 0.3 meter annulus of preformed bentonite blocks. The 
packages contain spent fuel pins from either 3 PWR assemblies or 8 BWR assemblies that have been disassembled and packaged in integral packaging facilities on the repository surface. (Costs of disassembly and packaging are included in repository costs.) The number of packages stored range from 53 thousand to 65 thousand, as shown in Table 1.2. The repositories also contain $\sim 60,000$ drums of contact-hand led TRU wastes and 12,000 packages (similar to spent fuel packages) of end fittings and hardware from disassembling the spent fue 1 assemb lies.

Unit costs for the reference repositories, stated in terms of dollars per kilogram heavy metal, are given in Table 1.3 for the reference cases and for alternative designs obtained from the sensitivity analysis. The latter cases represent combinations of extraction ratio (the ratio of room width to centerline distances between rooms), number of rows per room, and maximum therma 1 loadings, which result in minimum costs. The salt repositories have the lowest costs, followed in order of ascending costs by tuff, granite and basalt. The hard-rock repositories, (those in granite and basalt) are more expensive than salt and tuff repositories, mainly because of their higher excavation and hole drilling costs. Using higher thermal loadings and more cost-effective emplacement designs results in smaller cost differences among tuff, granite, basalt and salt, as shown in the sensitivity analyses, but the cost order remains unchanged.

Tuff repositories are estimated to cost less than those in basalt and granite chiefly because of the lower mining and hole drilling costs assumed for the lower density tuff. However, lack of data for this medium makes this

TABLE 1.3. Un it Cost Estimates for Generic Reference Repositories in Alternative Media, $\$ / \mathrm{Kg} \mathrm{HM} \mathrm{( \$ 1981)}$

\begin{tabular}{|c|c|c|c|c|}
\hline & Salt & Granite & Basa 1t & Tuff \\
\hline Reference & 82 & 98 & $107(103)(a)$ & 92 \\
\hline $\begin{array}{l}\text { Sensitivity Ana lysis } \\
\text { Minima }\end{array}$ & 78 & 90 & $99(95)(a)$ & 8 \\
\hline
\end{tabular}

(a) Costs if the basalt repository were expanded to dispose of an equivalent amount of spent fuel (see Table 1.2). 
conclusion highly uncertain. Granite and basalt repositories have similar hole drilling and excavating costs, and the principal reason for the overall cost difference between these media is basalt's lower thermal conductivity. In basalt, this conductivity difference results in larger minimum distances (pitches) between canisters to keep spent fuel cladding and media temperatures within safe guidelines and therefore reduces both total basalt repository emplacement capacity and achievable thermal loading. These effects can be seen by comparing the repository capacities shown in Table 1.2 for the different repositories. The above conclusions do not change when the costs in Table 1.3 are compared on a constant capacity basis. This can be seen by comparing the basalt costs in parentheses with the costs in other media. However, the unit basalt costs are reduced somewhat since fixed costs are spread over a 1 arger number of assemblies.

Finally, it should be noted that the differences in unit cost estimates among media are within the range of uncertainty associated with available data and therefore the cost ranking shown is tentative.

\subsection{SENSITIV ITY ANALYSIS RESULTS}

Based upon the design constraints imposed for this study, the sensitivity analyses indicate that the following are the most significant repository design variables, in order of cost sensitivity:

- package materials and package fuel capacity

- package diameter and length

- hole barriers and emplacement design

- cost of money

- limiting thermat loading criteria

- repository size.

Other variables having a significant, but less important impact on repository costs are mining costs, extraction ratios, and number of rows of waste emplacement per room.

The high cost sensitivity of the package design variable is illustrated in Figure 1.1. This figure shows that the unit repository costs would almost double by going from a simple carbon steel package containing 1 PWR or 2 BWR 


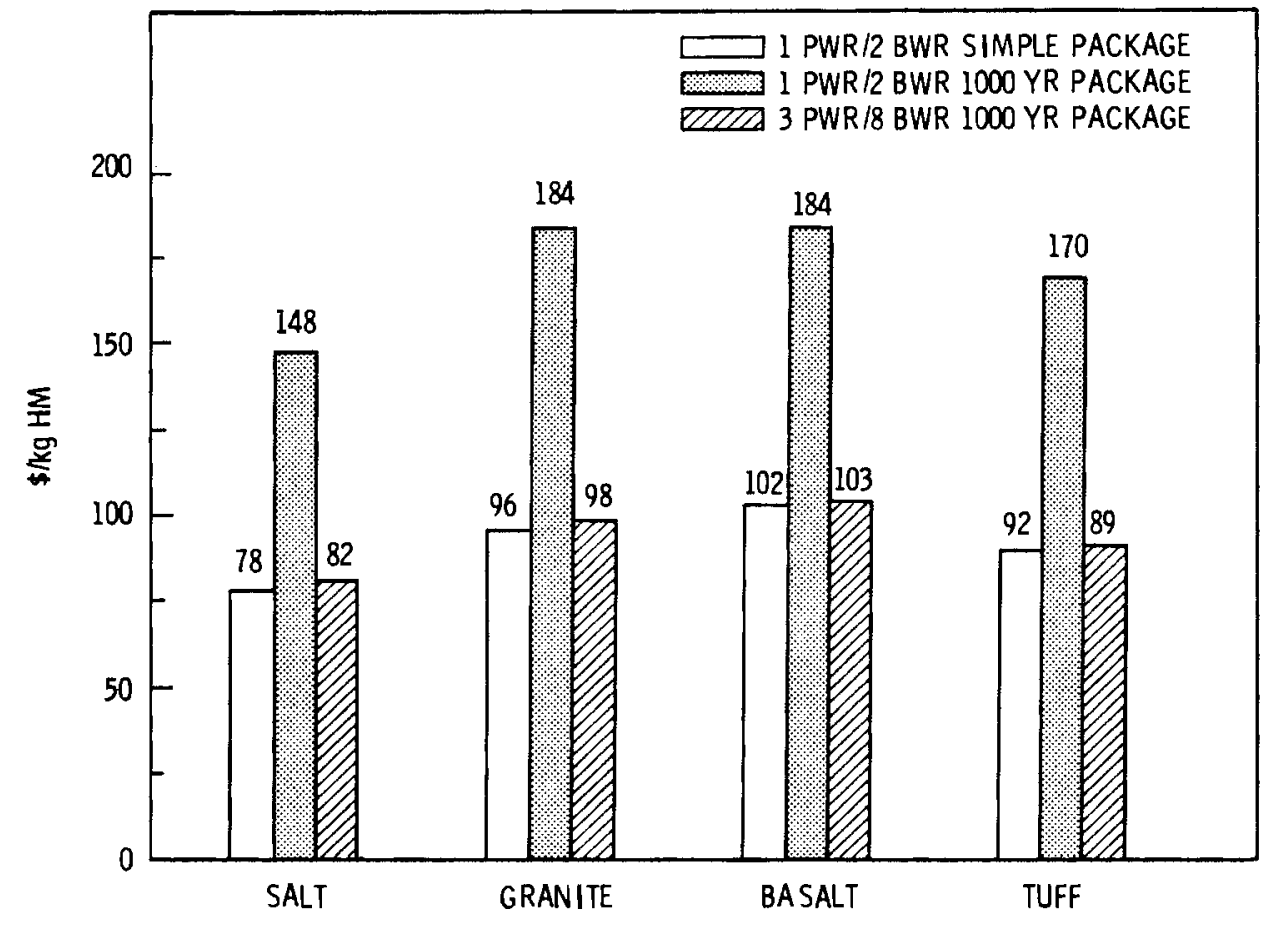

FIGURE 1.1. The Effect of Packaging Concept on Unit Repository Costs in Alternative Media

assemblies emplaced in a carbon steel sleeve to a titanium clad canister with a carbon steel sleeve surrounded by bentonite (1000-year borehole package) containing the same number of assemblies. This change would mean an additional $\$ 3$ to 5 billion per repository in total cost. This cost effect can largely be mitigated, however, by disassembling the spent fuel assemblies and increasing the spent fuel density per package. For a proposed package containing 3 PWR or 8 BWR assemblies (E.R. Johnson Associates 1981), unit costs would be reduced to approximately the same levels as estimated for the simple package design.

The above conclusions are based on input data that have various levels of uncertainty. Verification of this data was beyond the scope of this study. For cost-sensitive conclusions such as the effect of disassembly on unit costs, further work should be done to refine the data to substantiate these results. 


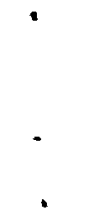




\subsection{INTRODUCTION}

This study addresses the economic impacts of using different geologic media for isolation of spent fuel. Media under active consideration include domed and bedded salt, granite, basalt and tuff. This section includes a general background, a description of the study approach, and a review of recent studies.

\subsection{BACKGROUND}

All nuclear generating stations create highly radioactive, thermally hot waste as a byproduct of electric power production. These wastes require iso1 ation from the biosphere for long periods of time. Based on conclusions in the GEIS (DOE 1980a), the preferred method of isolation is underground in deep, geologically stable, rock formations.

The U.S. Department of Energy (DOE) has established the National Waste Terminal Storage (NWTS) program to accomplish such waste isolation. The Office of NWTS Integration (ONI) has responsibility to coordinate this program, which has assumed national importance because of questions about the viability of nuclear power without a program to demonstrate the successful long-term isolation of its wastes. The Office of Nuclear Waste Isolation (ONWI) has responsibility for analyzing systems impacts of repository design under the NWTS program.

The recent Interagency Review Group (IRG) report (IRG 1979) recormended that regionaliy located repositories be considered and that additional research be done in alternative geologic media. As a result of these studies, five media are now under active consideration: domed salt, bedded salt, granite, basalt, and tuff. In 1981 ONWI commissioned the Pacific Northwest Laboratory (PNL) to make a preliminary estimate of the costs associated with constructing and operating repositories in the above media. These estimates were to be based on available information, with emphas is on determining the sets of conditions most favorable to each media (from a cost viewpoint). This task was accomplished by developing a repository cost model named RECON. With this model generic repository descriptions were selected and costs were estimated. 
Media and cost dependent parameters were then varied to determine key variables in terms of cost sensitivity. These results were used to investigate design changes that have the potential to reduce system costs.

This study is only intended to assess general economic effects. The economics of nuclear waste repositories are driven by many complex interacting factors that require detailed understanding before they can be applied to other situations. This study only attempts to define the effects and relationships of a limited number of these parameters. Therefore, unusual care must be taken to understand all assumptions and methodologies used when comparing the results of this study with estimates in other publications.

Also note that the quantity and quality of the input data varies substantially for the different media. Substantial cost and design data are available for salt media, but significantly less data are available for basalt; even less data are available for granite and very little data are available for tuff. Therefore, on ly large cost differences among media should be considered significant.

\subsection{REVIEW OF RECENT STUDIES}

Several studies have provided repository cost information. Detailed independent conceptual design studies have been done by Stearns-Rogers for a high-level waste (HLW) repository in domed salt (NWTSR1) (Stearns-Roger 1978), and by Kaiser Engineers for a spent fue 1 repository in bedded salt (NWTSR2) (Kaiser Engineers 1978a). The results of these studies were pooled to explain cost differences and to generate cost estimates for a HLW repository in bedded salt and a spent fuel repository in domed salt (Stearns-Roger-Kaiser 1979). The results of these studies were also combined in a more recent detailed Conceptual Reference Repository Design (CRRD) study by Bechtel (1979a).

Another set of independent conceptual design studies was completed by Parsons, Brinkerhoff, Quade and Douglas (1978) for HLW and spent fuel repositories in salt, basalt, granite and shale. These estimates were used as a beginning basis to develop another set of cost estimates for the GEIS on Commercial Radioactive Waste Management (DOE 1980a). Other related cost 
estimates include a special study of spent fuel disposal options (Bechtel 1979b), a preliminary spent fuel acceptance charge document (DOE 1978), a Statement of Position on Storage and Disposal of Nuclear Waste (DOE 1980b), a study to standardize estimates for different media (Brown 1980), a retrieval options study (Kaiser 1980), a disposal fee discount rate study (Forster and Cohen 1980), a depth optimization study (Thadani 1980) and draft studies of spent fuel disassembly (E. R. Johnson Associates 1981) and engineered waste package designs (Westinghouse 1981). Design engineering studies are currently under way for the Basalt Waste I solation and the Nevada Nuclear Waste Isolation Projects. Although reports for these studies are not available, data from these projects have been incorporated into this analysis.

A study similar to this one in several respects was done, based on information available at that time, by TRW in 1979 (see Forster 1979). The TRW study assessed the sources of uncertainty in repository costs and analyzed the effect of several general cost parameters. The study determined that the cost sensitive variables were, in order, economic factors, waste form, media, capacity and site-specific conditions. In this study those factors that are package and media dependent are analyzed in greater detail and their cost sensitivity is determined.

\subsection{APPROACH}

This study assembled the data from the foregoing references to define reference repository designs in bedded salt, domed salt, basalt, granite and tuff. Those design parameters that were not identifiable as media-dependent were held constant for each design. Some parameters have ranges that are media-dependent, but that have a sector of commonality (such as limiting thermal density and extraction ratio). In these cases values for the reference case were chosen to lie in the common sectors so that these factors were constant for all media. Where several values were reported, mid-range values for media-dependent variables were chosen. For example, unit direct mining costs of $\$ 10.50$ per tonne for salt were used out of a range of values of $\$ 9$ to 11.50

per tonne (Parsons, Brinkerhoff, Quade and Douglas 1978; Westinghouse 1981). In this study no attempt is made to define the risk of radiation exposure 
associated with the repository designs evaluated. Where possible, parameter values for the base cases were chosen to give the same level of risk, such as choice of package design. This selection was not possible, however, for some media-dependent variables such as depth, since the engineering design changes are too complex to simulate with the current model.

The reference repository costs were estimated using the data sources described above and the RECON repository economics model. This model is described in more detail in Section 3. In Section 4 the results of a cost comparison performed to test the model accuracy are described. The data and assumptions used for the reference baseline cases are given in Section 5 . Following this, a sensitivity analysis is performed in Section 6 for media and cost-sensitive variables in each medium. Based on the sensitivity analyses, cost-sensitive variables are identified. Cases using combinations of the variables are then evaluated to determine design changes yielding minimum system costs. 


\subsection{THE RECON MODEL}

This section briefly describes the computer model developed to perform the cost-comparison calculations for the alternative repository media. The level of data detail in the model allows preliminary cost estimates to be made. The model is useful in determining the driving cost influences in repositories and in establishing the parameters that significantly affect costs. A detailed description of the model and the data base will be published in a separate report to be issued in the next fiscal year (FY 82). That description will provide additional clarification of the model's capabilities and limitations.

The RECON model was constructed in a modular fashion to enhance its flexibility. Figure 3.1 is simplified schematic showing the different modules in the RECON model and the basic calculational flows. Calculations in one module, of course, affect and influence calculations in other modules, but these relationships are not shown in this simple figure. Each module is a cost center, meaning that cost calculations are accumulated for activities occurring in the module. The cost calculations as a function of time and waste type are performed internally in each module and then are sent to the center module, which is called HUB. The HUB module takes each cost calculation and develops the total cost, the cash flow, and the levelized unit cost for each cost center. These costs are then combined into appropriate categories and summarized in the output tables. The modular construction of the cost model enhances the accuracy because it breaks the cost calculations down into more detailed cost components. The modular construction also allows the model to be upgraded by adding modules or improving old ones with minimum reprogramming. The model is able to handle long repository operating and decommissioning periods, and multiple waste types and will calculate costs for multiple repositories. The basic logic and content of each of the modules in Figure 3.1 are described in more detail in the following subsections. 


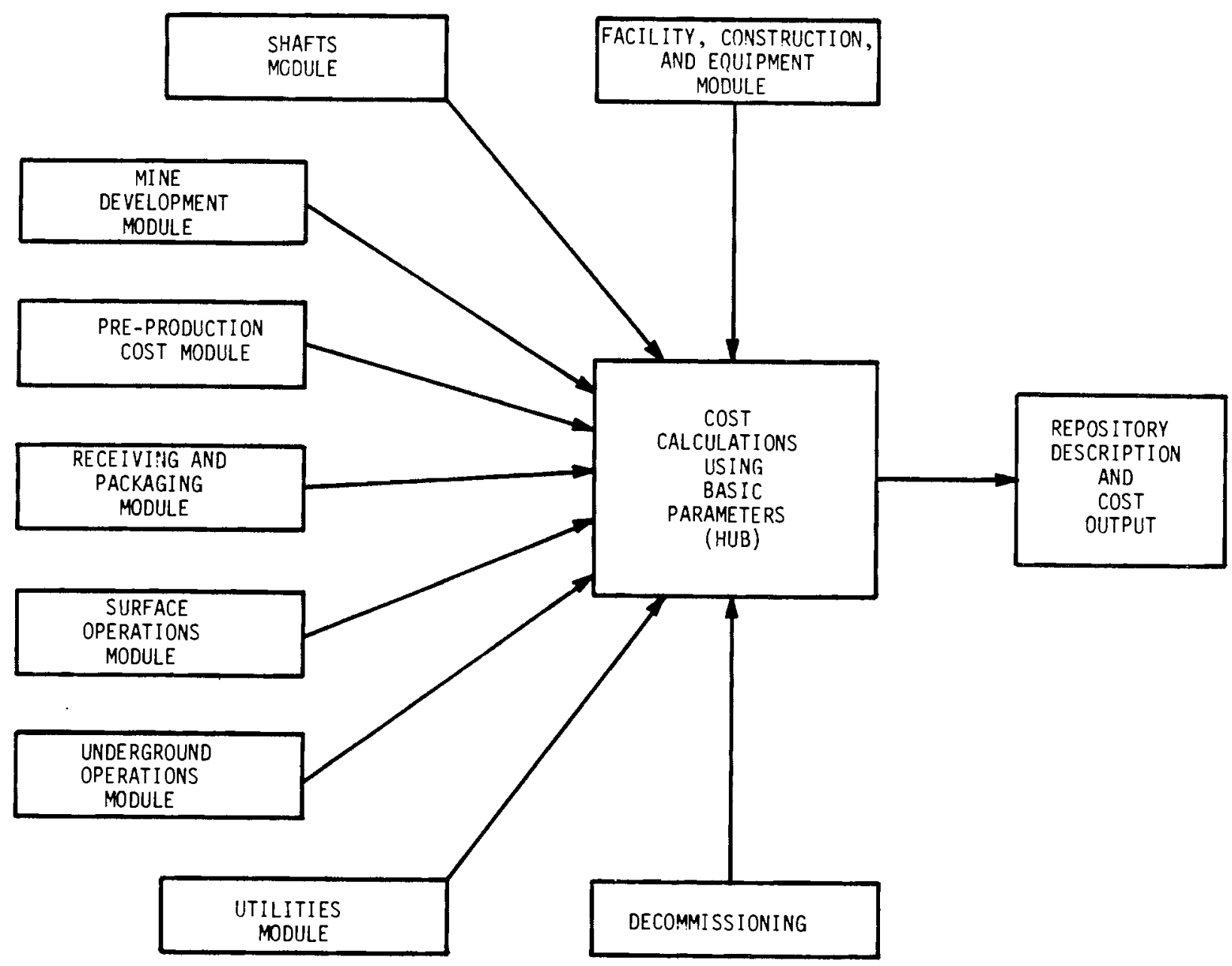

FIGURE 3.1. RECON Cost Model I llustration

\subsection{SURFACE OPERATIONS}

The surface operations module calculates three important repository parameters: the period of waste receipts and emplacement, the labor requirements and costs, and the cost of materials used in waste operations.

The model requires a schedule of waste available for receipt as input. The model attempts to process all of these wastes annually to the extent possible. Receipts are limited by the maximum number of receiving facility modules and the amount of wastes that can be processed per shift. Within these limits the model calculates the number of shifts that will be required to process the annual waste stream and the number of receiving modules required. The repository life is calculated by determining the annual 
repository area required for waste emplacement. The annual emplacement requirement is subtracted every year from a total available emplacement area with in the repository. When the total available emplacement area reaches zero, the repository is filled in that year.

Annual emplacement area requirements are determined by calculating canister emplacement densities by waste type and dividing these in to the total number of canisters available for emplacement in that year. Canister emplacement densities for remote-handled wastes of each waste type are determined by the pitch (the spacing between canisters in a row), the number of rows per room and the room spacing. Emplacement densities for contact-handled wastes are based on room width, room length, container dimensions and room height.

Canister emplacement density is limited by three thermal criteria. The far-field thermal limit constrains heat loading in terms of heat per unit of repository area, based on the total area of the repository occupied by each waste type, including the shaft pillar and main corridors. The near-field therma 1 limit constrains heat loading in terms of heat per unit area for the repository's emplacement area. This area includes the room, the rock pillars supporting the room, and the corridors servicing the room. The very-near-field thermal limit is defined by maximum temperatures in both the media and the canister. Depending on the media and the waste package configuration, one of these temperatures would be limiting. This latter criterion is expressed in the mode 1 in terms of a limiting pitch and is dependent on the number of rows per room, room spacing, thermal output per canister and package configuration.

Finally, the module calculates packaging and maintenance materials costs based on the number of canisters and the unit packaging and materials costs. Maintenance materials are costs for miscellaneous materials in the repository and are assumed to be equal to $60 \%$ of direct labor costs for the reference case. The model performs the above cost calculations for each waste type in the repository.

\subsection{MINE DEVELOPMENT}

The mine development module calculates the mining and rock logistic parameters for the repository. The mining requirements are based on a mine 
configuration specified by the total available repository area, room sizes, panel sizes, extraction ratio, drift, and main corridor dimensions, and exclusion areas. Exclusion areas include the main shaft pillar and other areas not available for mining rooms. The module logic is based on a rectangular layout for the rooms and corridors. Room heights are determined as a function of canister length. Corridor heights are specified as input. A differentiation is made between main corridors and drift corridors serving the rooms. Minedrock volume calculations assume a rectangular shape for the rooms and corridors.

Based on input determined timing, the model begins mining waste emplacement rooms before emplacement is required. After mining, the rock is transported either to the shaft for transportation to the surface or to backfilling operations if they have commenced. Calculations are made of rock hoisted to the surface, stored on the surface and transported offsite. Backfilling operations begin after a specified demonstration period. The module assumes that any rock needed for backfilling operations is supplied from rock mined for emplacement operations in that year. Rock volumes excavated in excess of that needed for backfilling are transported to the surface. Backfill volume calculations include the effect of rock expansion after it is mined, the addition of any supplemental backfill material, and the backfill density in the rooms. The module has the capability to examine different room sizes and extraction ratios for each waste type and assumes separate rooms for each waste type. The current module logic also assumes that the demonstration period will end sometime during the operational period. A subsequent version of the model will allow the demonstration period to extend beyond the end of waste operations to model recent proposed requirements in 10 CFR 60 . After operations have ceased or the demonstration period has ended, rock is brought down from the surface to backfill remaining rooms, corridors, and shafts during the decomissioning period. Cost calculations in this module are based on un it costs times volume or mass for direct mining, hauling, storage and backfilling. Fixed costs for mining equipment are also included. 
A flow diagram and description of the mine development logic in the RECON model as well as a description of interfaces between modules will be detailed in the follow-on report mentioned earlier.

\subsection{WASTE RECEIVING AND PACKAGING}

The waste receiving and packaging subroutine defines repository receiving and packaging capacity in terms of a unit module having a specified capacity and cost. Different modules are specified for receiving remote-hand led waste and contact-handled waste. The number of receiving and packaging modules required as a function of time is based on the number of waste units received and the capacities of each module. The model also adds receiving modules if these are required during operations. The model distributes the capital costs for these receiving module additions over a specified time period before the module is needed to simulate a capital cost addition.

\subsection{SHAFTS}

This subroutine estimates cost functions for excavating, lining and equipping the various shafts. The model delineates seven different types of shafts:

- men and materials

- mining ventilation

- canistered waste

- low-leve 1 waste

- development exhaust

- storage exhaust

- mine production.

The user initially specifies the number and description of each type of shaft desired. Included in this description are the shaft diameter, the shaft depth, the lined depth, the hoisting and shaft equipment cost, and the underground shaft station cost of each shaft. Cost functions are defined for excavation and lining costs as functions of depth and diameter for each medium. Cost functions for water control determine these costs as a function of medium. 
The shaft module also defines the number of additional waste or mine production shafts needed, based on shaft capacity and annual rock and waste volumes handled. Upgrading this section is planned to alternatively increase shaft diameter instead of excavating additional shafts.

\subsection{UNDERGROUND OPERATIONS}

The underground operations module describes emplacement operations underground for the repository. Options are provided for hole drilling, trenching, or simple placement in rooms, and other options can easily be added. For this study remote-handled waste packages were assumed to be placed in vertical holes in the floor and contact-handled waste packages to be simply stacked in the rooms. The package diameters for the various types of waste packages and the annular radii of hole barriers and backfill are required as input. Based on this data, the module determines the hole diameter for input to the hole dri1ling cost function.

Hole depth is also determined as a function of package length and cap length for input to the hole drilling cost function. Based on costs for a reference diameter and reference depth, unit barrier costs are determined as functions of their annular radii and the hole depth. Labor requirements for transporting and emplacing the wastes, hole barriers and underground waste handling equipment costs are all included as separate items.

\subsection{UTILITIES}

This module estimates utilities costs based on power, steam, water, and vehicle fuel requirements. Power costs are stated in terms of normal power operating levels in kilowatts for the different facilities in the repository. Time periods for power requirements are based on the average operating period for each type of facility each year. Utility requirements, which are a function of receipt rates such as power and fue 1 requirements for mining operations, are included as receipt rate functions. 


\subsection{FACILITY, CONSTRUCTION AND EQUIPMENT COSTS}

This module estimates construction costs for facilities and initial equipment and equipment replacement costs for capital equipment. Costs are estimated for each facility type. Equipment replacement costs are based on average equipment life for each type of facility. The timing of equipment replacement is also included to accurately model the cash flow requirements.

\subsection{PREPRODUCTION}

This module includes land acquisition, startup, and architect engineering costs. Startup and architect engineering costs are functions of equipment and total field costs, respectively. Field costs are defined as land, siting, construction, equipment and preoperational mine excavation costs.

\subsection{DECOMMISSIONING}

This module includes final backfilling, shaft sealing, facility decomissioning and surveillance costs. Final backfilling costs include backfilling of unfilled rooms, corridors and the shaft pillar area. Shaft sealing costs are included as total costs per shaft as a function of shaft diameter. Facility decommissioning costs are estimated as a percentage of total facility construction costs. Surveillance costs are assumed to be a constant annual cost over a specified time period after decommissioning is completed.

\section{$3.10 \underline{H U B}$}

This part of the program calls each of the above modules in the proper order so that calculational outputs from each module are available for input into succeeding modules. HUB also uses the results of the cost calculations in each module to assemble total costs, cash flows, and unit costs. After these calculations are made, HUB sends this data to the output table subroutines where they are printed. Output tables are printed for waste type for each repository as well as for repository totals. 



\subsection{MODEL VERIFICATION WITH CONCEPTUAL REFERENCE REPOSITORY DESIGN}

In this section the results of an analys is conducted to verify RECON are discussed briefly. Results of the recent CRRD study in salt were used for this verification because of the availability of design detail and bec ause the study represented the latest available integrated conceptual results (Bechtel 1979a, Vol I, pp 1.1-1.10, 2.1-2.4). The verification was made by using CRRD data to the maximum extent possible in the model. In a few areas where data were not available, data from the Stearns-Roger NWTSR1 study (Stearns-Kaiser 1979, VOI I) and the GEIS were used (DOE 1980a). A comparison of the verification results, with the CRRD costs stated in 1981 dollars, is shown in Table 4.1. The CRRD costs were escalated from 1979 dollars to 1981 dollars using a factor of 1.25, based on the average Gross National Product (GNP) deflator over this time period. The table shows excellent agreement using the model for materials costs, utility costs, shaft costs and contingencies. The total labor and overhead costs were somewhat underestimated, whereas equipment replacement costs and preproduction costs were somewhat overestimated. Total facility construction costs estimated by the model match CRRD estimates quite closely, with the waste facility building cost being somewhat higher, but the other construction costs being somewhat lower. The overall cost predicted by RECON was within about $1 \%$ of the CRRD estimate. This degree of accuracy should not be expected for other cost estimates, but gives some confidence in model results. Additional verification using at least one additional conceptual design study will be completed in the future. 
TABLE 4.1. Verification of RECON with CRRD

\begin{tabular}{|c|c|c|c|}
\hline Cost Area & $\frac{C R}{1979 \$}$ & $1981 \$$ & Benchmark \\
\hline $\begin{array}{l}\text { Total Labor \& } \\
\text { Overhead (a) }\end{array}$ & 1173 & 1466 & 1335 \\
\hline $\begin{array}{l}\text { Supplies \& Maintenance } \\
\text { Materials }\end{array}$ & 989 & 1236 & 1276 \\
\hline Utilities & 234 & 292 & 271 \\
\hline Equipment Replacement(b) & 150 & 187 & 245 \\
\hline Total Operating & 2546 & 3181 & 3127 \\
\hline Shafts & 139 & 174 & 167 \\
\hline Other Construction & 260 & 325 & 266 \\
\hline Waste Facility & 181 & 226 & 270 \\
\hline Preproduction & 90 & 113 & 237 \\
\hline Contingencies $20 \%$ & 600 & 750 & 751 \\
\hline Subtotal Construction & 1270 & 1588 & 1691 \\
\hline Total & 3816 & 4769 & 4818 \\
\hline
\end{tabular}

(a) Includes surface and underground labor, direct mining, backfilling hoisting, and hole drilling costs.

(b) Included in capital in model estimate. 


\subsection{REFERENCE CASES}

In the following section the reference cases used for the sensitivity analyses are described. Included in the section are generic repository descriptions, the data inputs and sources, and detailed results for the cases. The reference repository conditions are not optimized to each medium and the cost differences shown in the section will change as parameters are optimized.

\subsection{REFERENCE CASE DESCRIPTIONS}

The reference case repositories are assumed to be 2000-acre repositories located on a generic site. The repositories are assumed to start construction in 1990 and to start operations in 1995. Based on model determinations, the repositories are assumed to be filled in year 2022 for salt, 2021 for granite, 2018 for basalt, and 2021 for tuff. Each repository is assumed to have five shafts. For the reference cases all repositories assume a 1000-year, borehole package design. The repository designs assume that the spent fuel is transported to the repository where it is disassembled and packaged prior to emplacement. The repository layouts underground assume a layout similar to that used for the CRRD study in salt (Bechtel 1979a, Vol 4). Possible differences in repository layout caused by different media properties were not included in the scope of this study. The costs calculated for the reference cases are undiscounted and unescalated and are stated in 1981 dollars.

Al1 repositories assume a nominal 5-year demonstration period between emplacement and backfilling of rooms. Recent NRC guidelines have proposed a 50-year demonstration period. The effect of the demonstration period on costs is not explicitly addressed in this study; however, requiring a longer demonstration period with monitoring and potential remining costs for some media would clearly contribute to higher total costs. Decommissioning and sealing of the repository is assumed to commence after emplacement operations cease and would require five years to complete. For comparability, the base case assumes that mine air in all the repositories is conditioned (cooled) prior to 
being sent into the repository, although actual air-conditioning requirements may be site specific. Air-conditioning requirements are based on CRRD data (Bechte 1 1979a).

\subsection{DATA DESCRIPTION AND SOURCES}

In this section the data sources and their combination in the reference repository cost estimates are explained. A more detailed delineation and explanation of the data itself will follow in a backup volume.

Part of the rationale for developing reference cost estimates that can be compared to each other is that the data from conceptual repository designs are not all consistent. That is, the repositories are different sizes, start at different times, have different dollar bases for their cost estimates and make different assumptions with regard to demonstration periods, thermal limits, and other significant parameters. This study attempts to combine all the data sources and to put the data together in a consistent fashion to develop comparable cost estimates.

Parameters that are not readily identifiable as media dependent are held constant for each of the reference cases to allow comparisons of repository costs under similar sets of assumptions. Of necessity, occasionally some assumptions had to be made that data from different sources were compatible. Design bases were examined where data were available to validate this assumption to the extent possible.

\subsubsection{Facilities}

Surface facility descriptions, basic repository layout, shaft functions, diameters and capacities, basic labor requirements, utility requirements, and rock storage areas are based on CRRD designs and data. Facility construction costs and equipment costs by facility are derived from estimates in ONWI-76 for NWTSR1 (Stearns-Kaiser 1979). Equipment life is assumed to be 15 years except for mining equipment life, which was 8 years. Construction, shaft excavation and preoperational mine excavation schedules are based on CRRD estimates. Repository depths in salt, basalt and tuff are based on depths 
described in current conceptual design studies for candidate sites in those media. The granite repository is assumed to be at a depth similar to that for basalt.

\subsubsection{Packaging}

The repository design assumes an integral packaging facility at the repository. The waste handling building on the repository surface consists of modular receiving facilities for remote-handled waste and contact-handled waste, modular packaging facilities, and other support facilities located in the waste handling building. Each spent fuel receiving modules has a capacity of $\sim 2,000$ tonnes and costs $\$ 36$ million. The contact-handled waste receiving module has a capacity in excess of 6,000 drums per year and costs $\sim \$ 13 \mathrm{mil}$ lion. The packaging module costs $\sim \$ 52$ million with a capacity of 2,000 tonnes per year. The packaging facility cost estimates are derived from data in the reconciliation cost study (Stearns-Kaiser 1979), which was derived from Kaiser Engineers' conceptual design report (Kaiser 1978b). The original Kaiser packaging facility estimate was for a stand-alone facility. The reconciliation study factored this design to derive costs for a packaging plant that would be colocated with the repository. An estimate of the packaging facility cost for a facility integral with the repository was made from the colocated cost estimate by subtracting costs for auxiliary buildings, utilities, and other support structures. The derived cost estimate for a facility that is 4,000 tonnes per year (two modules) agrees closely with cost estimates made in the CRRD design study (Bechtel 1979a, Vol I) for an integral waste handling and packaging facility with a similar volume.

The RECON model calculates the number of receiving modules required, based on the percentage of rail versus truck casks received and the capacities of the casks. For this study $90 \%$ of cask shipments were assumed to be by rail in NLI 10/24 and IF-300 shipping casks. (a) Truck casks were assumed to be typical of NLI $1 / 2$ casks.

(a) NLI 10/24 refers to a National Lead Industries spent fuel shipping cask with a capacity of 10 PWR or 24 BWR spent fuel assemblies. The IF -300 cask will hold 7 LWR or 17 BWR assemblies. 
NWTS criteria include package standardization and state that packages are to be standardized to the extent practical for safety and economic reasons. Because of these criteria and because data were not available on media-specific package designs and costs, package and emplacement designs were assumed to be the same for all media. However, media-specific designs are being developed within the above criteria and these will be included in updated estimates as data become available. Spent fuel assemblies were assumed to be packaged in titanium-clad, carbon steel canisters as described in a Westinghouse design (Westinghouse 1981). These canisters are 0.4 meters in diameter and 4.3 meters long for PWR assemblies and 4.7 meters long for BWR assemblies. Based on a package design with a similar internal diameter in ( $E$. R. Johnson Associates 1981), the packages were assumed to hold 3 disassembled PWR assemblies or 8 disassembled BWR assemblies. Based on Johnson's estimates of the additional costs for packaging and handling these containers, the facility costs were increased by $\$ 45$ million. These costs are also assumed to cover the additional capital costs required for the packaging facility, shaft hoists, and transporters to handle the heavier canisters. Whether these estimates include additional shielding for the transport casks is not known. In their estimates of the impacts of packaging 3 PWR assemblies or 8 BWR assemblies per canister, E. R. Johnson Associates (1981) concluded that overall labor costs would be reduced by $\$ 1.74$ to $\$ 3.34$ million per year depending on the operating level. The reduction in labor costs results principally because of the reduction in the number of packages that are required to be handled. These cost reductions assume the CRRD operating cost levels as a base line. Since the basic labor requirements for the reference cases are also based on the CRRD, labor requirements for these cases were reduced correspondingly. In addition to the reduced labor costs, utility costs and underground equipment costs were reduced by $\$ 1.2$ million and $\$ 5.6$ million, respectively, based on the reduced number of packages handled.

Costs of the titanium-clad packages were estimated by Westinghouse to be $\sim \$ 20,000$ each (Westinghouse 1981). The cost of cages to hold the disassembled spent fuel pins were estimated by (E. R. Johnson Associates 1981) to cost 
$\$ 1,000$, resulting in a total cost of $\sim \$ 21,000$ for a 4.7 meter-1ong canister. The cost for the PWR canister was reduced and proportioned to its shorter length, resulting in a cost of $\sim \$ 20,000$ for this canister.

\subsubsection{Fuel Receipt Schedule}

The fuel receipt schedule is based on a regional repository concept and is derived by assuming one third of ORNL PM-6008 projections as reported in the CRRD (Bechtel 1979a, Vol. I). For this study receipts were adjusted to reflect a 1995 startup with backlog worked off over a 10-year period. The receipt schedule is shown in Table 5.1. Receipts for the first five years are shown at a small nominal level to reflect the initial startup and proving-out period of the repository. The 10-year period used to work off the backlog begins at the end of the repository proving-out period.

The ORNL projections provide data to the year 2020. Since repository operating periods for some of the cases were anticipated to extend past the year 2020, the projections were extended assuming an annual increase in receipts equal to the average rate of increase from year 2017 to 2020 . The schedules shown in Table 5.1 reflect the schedule of available ten-year-old and older fuel. Calculated repository receipts are shown in Section 5.3.1.

\subsubsection{Mining and Rock Handling}

This section describes the data sources and assumptions for mining, underground haulage, rock hoisting, surface disposal, and backfilling. Mining cost estimates in the model are subdivided into direct mining costs and mining equipment costs. Direct mining costs include all direct costs for labor and materials required to excavate and transport the rock. Also included are costs to drain, ventilate and develop the tunnel and indirect costs for mining support functions. Costs for direct mining are based on Parsons, Brinkerhoff, Quade and Douglas (1978, Vol 18) cost estimates escalated to 1981 dollars. These estimates were somewhat dated, but provided a consistent set of estimates for three of the four media considered in this analysis (salt, granite, basalt). Estimates furnished by Bechtel $(a)$ of 9 and $16 \$ /$ tonne for

(a) These cost estimates were furnished by Bechtel National Inc. as backup data for DOE 1979, Vol 4. 

TABLE 5.1. Spent Fue I Ten Years Old or Older, Availabje for Regional
Repository Disposal (One Third of Total)(aa) for Region

\begin{tabular}{|c|c|c|}
\hline Year & $\begin{array}{c}\text { PWR Fuel } \\
\text { Assemblies } \\
\end{array}$ & $\begin{array}{r}\text { BWR Fuel } \\
\text { Assemblies } \\
\end{array}$ \\
\hline 1990 & 0.0 & 0.0 \\
\hline 1991 & 0.0 & 0.0 \\
\hline 1992 & 0.0 & 0.0 \\
\hline 1993 & 0.0 & 0.0 \\
\hline 1994 & 0.0 & 0.0 \\
\hline 1995 & 2400.0 & 3600.0 \\
\hline 1996 & 2400.0 & 3600.0 \\
\hline 1997 & 2400.0 & 3600.0 \\
\hline 1998 & 2400.0 & 3600.0 \\
\hline 1999 & 2400.0 & 3600.0 \\
\hline 2000 & 3429.0 & 4580.0 \\
\hline 2001 & 3636.0 & 4884.0 \\
\hline 2002 & 3857.0 & 5207.0 \\
\hline 2003 & 4078.0 & 5530.0 \\
\hline 2004 & 4326.0 & 5894.0 \\
\hline 2205 & 4586.0 & 6276.0 \\
\hline 2006 & 4846.0 & 6658.0 \\
\hline 2007 & 5100.0 & 7036.0 \\
\hline 2008 & 5363.0 & 7427.0 \\
\hline 2009 & 5623.0 & 7809.0 \\
\hline 2010 & 5051.0 & 7113.0 \\
\hline 2011 & 5206.0 & 7336.0 \\
\hline 2012 & 5358.0 & 7553.0 \\
\hline 2013 & 5516.0 & 7782.0 \\
\hline 2014 & 5674.0 & 8005.0 \\
\hline 2015 & 5833.0 & 8229.0 \\
\hline 2016 & 5993.0 & 8458.0 \\
\hline 2017 & 6149.0 & 8681.0 \\
\hline 2018 & 6288.0 & 8904.0 \\
\hline 2019 & 6423.0 & 9127.0 \\
\hline 2020 & 6561.0 & 9268.0 \\
\hline 2021 & 6698.0 & 9463.0 \\
\hline 2022 & 6835.0 & 9658.0 \\
\hline 2023 & 6972.0 & 9853.0 \\
\hline 2024 & 7109.0 & 10048.0 \\
\hline 2025 & 7246.0 & 10243.0 \\
\hline 2026 & 7383.0 & 10438.0 \\
\hline 2027 & 7520.0 & 10633.0 \\
\hline 2028 & 7657.0 & 10828.0 \\
\hline & 7794.0 & 11023.0 \\
\hline 2030 & 7931.0 & 11218.0 \\
\hline
\end{tabular}

(a) Bechtel 1979a, Vol 1. 
excavation costs in bedded salt and basalt were in substantial agreement with the OWI estimates. A direct mining cost of $\$ 16$ per tonne in basalt was estimated by Kaiser-Parsons for the NWRB repository cost estimate reported in the appendix. Mining cost estimates for tuff media were not available and direct mining cost estimates midway between the values for salt and basalt were used for this medium (since the density of welded tuff lies between the density of salt and basalt). Direct mining cost estimates used in this analysis were $\$ 10.50$ per tonne for salt, $\$ 17$ per tonne for granite and basalt, and $\$ 13.75$ per tonne for tuff. For mining costs in salt, a continuous miner is assumed to be used; in all the other estimates drilling and blasting techniques are assumed in mining the repository. For consistency the mining equipment costs were also based on the report by Parson, Brinkerhoff, Quade and Douglas (1978, Vol 18). Escalated to 1981 dollars these costs were $\$ 43$ million in salt, $\$ 70$ million in granite, and $\$ 80$ million in basalt. Equipment costs similar to those for granite were assumed in tuff. The salt cost estimates agreed well with estimates reported in Stearns-Kaiser (1979) (escalated to 1981 dollars) of $\$ 37.9$ milition for mine development equipment in domed salt and $\$ 44.8 \mathrm{mil}$ lion for mine development equipment in bedded salt. Maximum extraction ratios of $25 \%$ in salt and $55 \%$ in granite and basalt are given in Kaiser (1980); however, in this analys is extraction ratios only as high as $40 \%$ in hard rock media were analyzed.

Direct hoisting costs were estimated based on data and relationships in Thadani (1980). These data give cost relationships as a function of repository depth. For the 600-meter repository depth in salt, costs were estimated at $\$ 0.27$ per tonne in 1981 dollars. Corresponding estimates for 1,000-meter depths for repositories in granite and basalt were $\$ 0.42$ per tonne for both granite and basalt. Costs for an 875-meter-deep shaft in tuff were $\$ 0.39$ per tonne. These costs are somewhat lower than hoisting costs reported in Parsons, Brinkerhoff, Quade, and Douglas (1978, Vol. 18) of $\$ 0.58$ per tonne; however, the costs differences are small and do not have a significant impact on the overall cost estimates.

Backfilling cost estimates are derived from DOE (1979). These estimates are based on using continuous backfilling machines that pile the backfill into the rooms. Based on the above data, estimates of $\$ 9.40$ per cubic meter, 
$\$ 15.70$ per cubic meter, $\$ 16.1$ per cubic meter and $\$ 14.10$ per cubic meter were developed for salt, granite, and basalt and tuff, respectively, in 1981 doll ars.

Surface disposal charges for managing the mined rock on the surface were based on estimates in the CRRD (Bechtel 1979a) for salt and in Parsons, Brinkerhoff, Quade and Douglas (1978, Vol. 18) for the hard rock media. The CRRD estimates charges were used since these represented more recent designs for handling the leaching problems associated with surface storage of salt. Significant leaching problems are not anticipated with the other media. Escalated to 1981 dollars these studies report costs of $\$ 1.75$ per tonne for salt and $\$ 0.70$ per tonne for basalt and granite. Since estimates for rock hoisting, backfilling, and surface disposal were not available for tuff, cost estimates for hard rock media were assumed to be representative of costs in tuff.

Data on rock densities for salt, granite, and basalt are based on information contained in Brown (1980). Estimates of tuff rock densities were based on discussions with Nevada Nuclear Waste Isolation personnel. The values used in this report are $2.16,2.67,2.77$ and $2.4 /$ tonnes $/ \mathrm{m}^{3}$ for salt, granite, basalt and tuff, respectively.

\subsubsection{Shafts}

In this section the data used to estimate shaft excavation, lining, water control costs, and shaft hoisting equipment costs are discussed. Underground station costs are included in Section 5.2.6. Shaft excavation, lining, and water control cost functions used in the model are based on plots derived from Parsons, Brinkerhoff, Quade and Douglas data (1978, Vol. 18). The cost data are based on conventional drill and blasting excavation techniques. Equipment costs for shafts in salt are based on data in ONWI-76 (Stearns-Kaiser 1979). Shaft equipment costs for the deeper repositories in the other media were derived by factoring the shaft equipment costs in salt. These factors were derived from data in Thadani (1980), which gives shaft equipment costs as a function of repository depth. 


\subsubsection{Underground Waste Operations}

This section describes costs for equipment, manpower, and materials used to transport the waste underground and to emplace it in vertical holes drilled in the floor. Cost estimates for the shaft stations underground are based on estimates given in Brown (1980) for the NWTSR2 repository design. Costs of transporters to transfer casks from the shaft stations and to emplace them in the hole are based on estimates given in Westinghouse (1981). An additional allowance of $\$ 1$ million was made for engineered barrier emplacement equipment. Underground equipment life is conservatively estimated to be 8 years. Underground labor costs are based on labor requirements specified in the CRRD (Bechtel 1979a) estimate.

Bechtel backup data, derived for the GEIS on Commercial Radioactive Waste Management (DOE 1980a; DOE 1979), provided hole drilling and sleeve emplacement costs. These data estimate the cost of the hole drilling in hard rock media, such as basalt, to be from $\$ 12,000$ to $\$ 13,000$ for a 4-foot diameter, 21-foot deep hole. However, other cost estimates received from Kaiser Engineers for drilling similar holes in basalt are at $\sim \$ 6500$ per hole. The GEIS hole drilling cost estimates were used in this study for conservatism and because they represented a set of consistent data for three of the four media studied. Hole drilling costs for repositories in tuff were assumed to lie between hole drilling costs for repositories in hard rock and repositories in salt, since costs are probably a function of media density.

The reference repository emplacement design assumes that preformed bentonite blocks are placed around the sleeves in the holes. Costs of $\$ 2800$ per hole for bentonite blocks having a 0.3 meter thickness given in Westinghouse (1981) are used as the bentonite cost basis in this study. This cost included both the cost of materials and fabrication. Costs for carbon steel sleeves placed in the hole are based on sleeve cost estimates for similar diameter packages given in Westinghouse (1981).

\subsubsection{Emplacement Configurations}

In this section the emplacement configurations used in the reference repository cases are discussed. Emplacement configurations are functions of 
limiting thermal guidelines and rock strengths. The model uses the results of external heat transfer calculations in defining the relationship between the extraction ratio and the hole pitch. For the reference case packages containing 3 PWR or 8 BWR elements per package, very little published thermal data exist. However, for a repository in basalt, minimum hole pitches for these packages have been estimated based on unpublished data developed by Kaiser Engineers in developing conceptual designs for the basalt waste isolation project. Based on these data and also on data from reference repository conditions reports developed by the reference repository conditions interface working groups in ONWI, minimum hole pitches have been estimated for repositories in granite, tuff, and salt. These minimum hole pitches are 5.0 meters in salt, 5.5 meters in granite, 3.6 meters in tuff, and 6.0 to 9.0 meters in basalt (the 6 -meter spacing is for the lower heat density BWR canisters). These spacings are tentatively estimated to result in media temperatures at or below $200^{\circ} \mathrm{C}$ and spent fue $1 \mathrm{clad}$ temperatures at or below $300^{\circ} \mathrm{C}$. Based on the thermal data available to date, the spacing in basalt appears to be limited by very-nearfield criteria, whereas the spacing in the other media is limited by near-field heat criteria. The minimum hole pitches given above are based on placing 2 rows in a room, a $20 \%$ extraction ratio, and a room width of 5.5 meters. Since the basalt canister spacings are very-near-field limited, decreasing the pillar width between rooms (increasing the extraction ratio) would require wider spacings between canisters to remain within the media and cladding temperature limits. Preliminary data on temperature-pitch-extraction ratio relationships have been developed by Kaiser as mentioned above and are used as the basis for the parametric analysis of basalt in this report.

In this study, extraction ratios for the other 3 media are assumed to be increased to $40 \%$ by decreasing pillar widths, without increasing the minimum pitch distance until the areal thermal loading limits are reached. This assumption is tentative since the conditions at which the very-near field criteria might become limiting are not known for these media.

For all repositories the near-field thermal loading limit is assumed to be $60 \mathrm{~kW}$ per acre, which is equivalent to a far-field thermal load of $50 \mathrm{~kW}$ 
per acre (see thermal loading definition in section 3.1). All 3 thermal loading limits are at or below recommended limits published in the GEIS on commercial radioactive waste management (although for conservatism the GEIS used $40 \mathrm{~kW} /$ acre for far-field loading in salt) and are recommended in the reference repository conditions working group studies. Additional detail on pitch versus extraction ratio data will be given in the backup data volume, which will be published later.

\subsubsection{Other Reference Case Assumptions}

Other significant reference case parameters not discussed above are presented in this section. Land costs for the reference cases were assumed to be the same for all media. Land costs of $\$ 31$ million were derived from the NWTSR1 estimate published in Stearns-Kaiser (1979). Data on shaft sealing costs were not yet available. Shaft sealing costs have been estimated in this study at $\$ 1$ million per meter in diameter for each shaft. Surveillance costs, also included in the reference case studies, were estimated at $\$ 100,000$ per year for 300 years. This time period is conservatively long, but the effect on total cost is minimal. The reference cases assume emplacement of contacthandled TRU waste in 55-gallon drums as well as emplacement of spent fuel. Maximum drum receipt rates are assumed to be 5 drums per shift. The drums would be stacked in rooms having the same dimensions as the rooms for storing spent fue 1. Approximately 5200 drums would be stored per room.

Disassembly of the spent fuel assemblies results in end fittings and other hardware components as a separate waste stream. These components are assumed to be packaged without compaction (using sand as a filler) in packages similar to those for spent fuel. Based on hardware volumes per assembly developed for the GEIS (DOE 1979, Vol. 5), hardware from 16 PWR assemblies or 39 BWR assemblies can be packaged per reference canister. Based on GEIS data, heat densities for these canisters are $\sim 0.12 \mathrm{~kW}$ per canister. According to E. R. Johnson Associates (1981), these packages are placed in holes similar to spent fuel, but without the liner.

The reference cases assume a $20 \%$ contingency estimate for al1 media since costs were estimated at the same level of detail. The effect of uncertainties 
in the data on overall costs is developed in the parametric analysis in Section 6 . The cost escalation factors used to escalate previously reported costs to 1981 dollars are shown in Table 5.2.

A comprehensive table listing all major parametric and cost inputs will be given in the follow-on document.

\subsection{RESULTS}

In the following section the cost results for the reference cases are discussed and explained using data generated by the program. Cost results are shown for total repository costs, annual repository cash flows, and unit costs.

\subsubsection{Total Costs}

Total costs for the repositories in alternative media in millions of 1981 dollars are shown in Table 5.3. Costs range from $\$ 7.6$ billion in salt to $\$ 9$ billion in granite. The largest portion of the total costs are in the surface operating costs, which include labor, maintenance materials, and package materials. These costs range from $33 \%$ to $42 \%$ of the total. The surface operating costs for basalt are somewhat lower than those for the other media because fewer packages are emplaced due to heat limitations. This difference is illustrated in Table 5.4, which shows total receipts in the repositories as a function of time. The repositories are filled in year 2022, 2021, 2018, and 2021

TABLE 5.2. Escalation Factors Based on GNP Deflator (West inghouse 1981)

\begin{tabular}{cc} 
Beginning of Year & \multicolumn{2}{c}{$\begin{array}{l}\text { Factor to Con } \\
\text { Mid Year 1981 }\end{array}$} \\
\cline { 2 - 2 } 1976 & 1.53 \\
1977 & 1.44 \\
1978 & 1.34 \\
1979 & 1.25 \\
1980 & 1.15 \\
1981 & 1.05
\end{tabular}


TABLE 5.3. Tota 1 Costs for Reference Repositories in Alternative Media, Millions of 1981 Dollars

Repository Media

Salt Granite $\underline{\text { Basalt }}$ Tuff

Construction Costs For

Waste Receiving

Facilities

155.0

155.0

119.4

155.0

Waste Packaging

Facilities

206.4

206.4

154.8

206.4

All Other Surface

Facilities(a)

725.9

833.9

803.2

833.9

Shaft-Related

Facilities

166.7

123.3

170.3

115.4

Preoperational Mine Development Cost

\begin{tabular}{|c|c|c|c|}
\hline 26.3 & 48.3 & 52.3 & 34.9 \\
\hline 1280.3 & 1366.9 & 1300.0 & 1345.6 \\
\hline 3210.8 & 3110.6 & 2623.3 & 3110.6 \\
\hline 359.9 & 687.0 & 701.5 & 509.4 \\
\hline 789.8 & 1575.7 & 1326.4 & 1312.1 \\
\hline 300.2 & 302.3 & 277.6 & 296.2 \\
\hline 307.6 & 307.2 & 307.8 & 306.9 \\
\hline 122.9 & 139.0 & 138.5 & 132.1 \\
\hline 1274.3 & 1497.7 & 1335.0 & 1402.6 \\
\hline 7645.92 & 8986.44 & 8010.01 & 8415.45 \\
\hline
\end{tabular}

Tota ls

Construction Cost

Sub total

Surface Operating Costs (b)

Mining Operating Costs

Underground Operating Costs

Utility Costs

Preproduction Costs

Decommissioning and

Sealing Costs

Contingencies

(a) Includes site preparation, mined rock storage and equipment replacement. (b) Excludes utilities. 
TABLE 5.4. Annual Receipts and Emplacement Area Requirements for Reference Repositories in Alternative Media

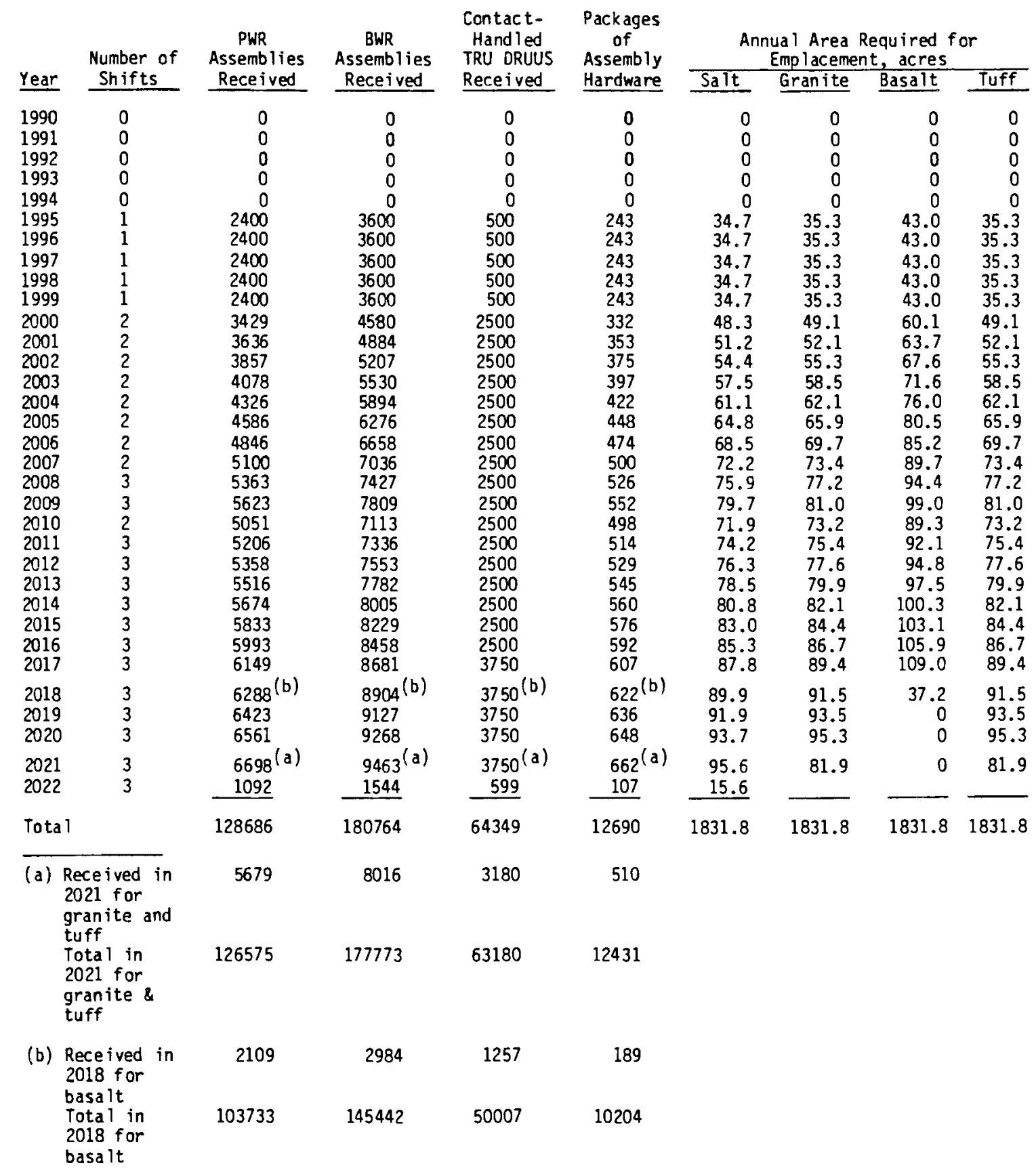


for salt, granite, basalt, and tuff, respectively. The shorter operating period for basalt results in lower surface operations costs. The reason for the shorter operating period in basalt can be seen by examining the annual area emplacement requirement shown in the same table. Emplacement area requirements for basalt (for the same amount of waste) are about $23 \%$ higher than in the other media. This larger emplacement area is due to the wider spacing of canisters in the rows caused by the very-near-field thermal limitations, as shown in Table 5.5. This table shows the actual canister spacing and near-field-thermal loading achieved in the repositories versus their limiting criteria. The canister spacings in salt, granite and tuff all exceed the minimum spacing and are limited by the near-field thermal limit. (The actual loading achieved is averaged over hardware and contact-handled waste, as well spent fuel, resulting in averages somewhat less than the maximum allowable for spent fue1). However, the spacing in basalt is limited by the minimum pitch based on very-near-field thermal limits.

The next most significant cost areas in Table 5.3 are the contingencies and underground operating costs. Contingencies account for about $17 \%$ of the total costs, and underground operating costs account for 10 to $18 \%$ of the total costs. Underground operating costs in salt are significantly lower than those

TABLE 5.5. Center-To-Center Canister Spacing and Limiting Placement Criteria for the Reference Cases in Alternative Media

\begin{tabular}{|c|c|c|c|c|c|}
\hline Media & Waste Type ${ }^{(a)}$ & $\begin{array}{c}\text { Center-To- } \\
\text { Center Spacing } \\
\text { in Rows, m } \\
\end{array}$ & $\begin{array}{c}\text { Very Near } \\
\text { Field Spacing } \\
\text { Limit } \\
\end{array}$ & $\begin{array}{c}\text { Actual Near } \\
\text { Field Loading } \\
\text { in Repositary } \\
\mathrm{kW} / \mathrm{acre} \\
\end{array}$ & $\begin{array}{c}\text { Near Field Thermal } \\
\text { Loading Limit }(b) \\
\text { Used kW/acre } \\
\end{array}$ \\
\hline Salt & $\begin{array}{l}\text { PWR Fuel } \\
\text { BWR Fue 1 } \\
\text { Hardware }\end{array}$ & $\begin{array}{l}6.02 \\
5.25 \\
2.43\end{array}$ & $\begin{array}{l}5.00 \\
5.00 \\
2.40(b)\end{array}$ & 56 & 60 \\
\hline Granite & $\begin{array}{l}\text { PWR Fuel } \\
\text { BWR Fue l } \\
\text { Hardware }\end{array}$ & $\begin{array}{l}6.77 \\
5.81 \\
2.43\end{array}$ & $\begin{array}{l}5.50 \\
5.50 \\
2.40(b)\end{array}$ & 55 & 60 \\
\hline Basalt & $\begin{array}{l}\text { PWR Fuel } \\
\text { BWR Fue 1 } \\
\text { Hardware }\end{array}$ & $\begin{array}{l}9.03 \\
6.02 \\
2.43\end{array}$ & $\begin{array}{l}9.00 \\
6.00 \\
2.40(b)\end{array}$ & 45 & 60 \\
\hline Tuff & $\begin{array}{l}\text { PWR Fuel } \\
\text { BWR Fuel } \\
\text { Hardware }\end{array}$ & $\begin{array}{l}6.77 \\
5.81 \\
2.43\end{array}$ & $\begin{array}{l}3.60 \\
3.60 \\
2.40(b)\end{array}$ & 55 & 60 \\
\hline
\end{tabular}

(a) Contact-handled TRU wastes are not emplaced in holes and therefore are not included in this table.

(b) Based on structural limits rather than heat. 
in the hard rock media mainly because of the lower hole-drilling costs in the softer salt media. Total construction costs are about $16 \%$ of total repository costs or $\$ \$ 1.3$ billion. Four receiving and packaging modules are required in the salt, granite and tuff repositories for a cost of $\sim \$ 360$ million for each repository. Because the basalt repository stores less fue 1 and because more spent fuel is available for storage toward the end of the repository life, on ly three receiving and packaging modules are required for the basalt repository, for a total cost of $\sim \$ 270 \mathrm{million}$. The cost differences anong the different media for the all-other-surface-facilities category are mainly due to differences in mining equipment costs. Table 5.6 shows the subdivision of shaft-related facilities costs for the alternative media. Shaft sinking costs are higher in the hard rock media than in salt because of the difficulty in excavation; however, water control and lining costs are higher in the salt repository shafts. Information received subsequent to the analys is indicates that water-control costs in other media could equal or exceed those in salt. This information will be factored into future reports. Equipment costs are higher in the hard rock media because of greater depth.

The preoperational mine development costs in Table 5.3 (which do not include underground $f a i l i t y$ construction) are greater in the hard rock media than in salt because of the greater difficulty in mining these media. This difference is also reflected in mining operating costs shown in the table. Cost differences among media for utility, preproduction, and decommissioning costs are of minor significance. A summary of mine development and rock handling data for the reference cases is shown in Table 5.7. Total rock mined ranges from 23.8 million tonnes for salt to $29.9 \mathrm{milli}$ on tonnes for granite. Rock remaining on the surface after operations are completed ranges from 9.4 million tonnes for salt to $13.8 \mathrm{milli}$ on tonnes for granite.

\subsubsection{Cash Flow}

In this section the results of the cash flow analyses made for the reference repositories in the alternative media are described. These analyses are 
TABLE 5.6. Shaft Cost Estimates for the Reference Case, Millions of 1981 Dollars

\begin{tabular}{|c|c|c|c|c|c|}
\hline \multirow{2}{*}{ Shaft Type } & \multirow[b]{2}{*}{ Cost Type } & \multicolumn{4}{|c|}{ Geologic Media } \\
\hline & & Salt & Granite & Basalt & Tuff \\
\hline Men \& Materials & $\begin{array}{l}\text { Sinking } \\
\text { Water Control } \\
\text { Lining } \\
\text { Equipment } \\
\text { Subtotal }\end{array}$ & $\begin{array}{r}12.1 \\
14.0 \\
8.2 \\
15.2 \\
49.5\end{array}$ & $\begin{array}{r}14.9 \\
0.3 \\
0.6 \\
20.9 \\
36.7\end{array}$ & $\begin{array}{r}22.7 \\
1.3 \\
1.2 \\
20.8 \\
46.0\end{array}$ & $\begin{array}{r}13.0 \\
1.3 \\
0.5 \\
19.4 \\
34.2\end{array}$ \\
\hline Mine Ventilation & $\begin{array}{l}\text { Sinking } \\
\text { Water Control } \\
\text { Lining } \\
\text { Equipment } \\
\text { Subtotal }\end{array}$ & $\begin{array}{r}12.3 \\
11.1 \\
6.6 \\
4.5 \\
34.5\end{array}$ & $\begin{array}{r}15.2 \\
0.3 \\
0.6 \\
6.1 \\
22.2\end{array}$ & $\begin{array}{r}23.3 \\
1.3 \\
1.2 \\
6.1 \\
31.9\end{array}$ & $\begin{array}{r}13.4 \\
1.3 \\
0.6 \\
5.7 \\
21.0\end{array}$ \\
\hline Waste Transport & $\begin{array}{l}\text { Sinking } \\
\text { Water Control } \\
\text { Lining } \\
\text { Equipment } \\
\text { Subtotal }\end{array}$ & $\begin{array}{r}11.8 \\
7.3 \\
4.3 \\
13.1 \\
36.5\end{array}$ & $\begin{array}{r}15.0 \\
0.3 \\
0.6 \\
17.9 \\
33.8\end{array}$ & $\begin{array}{r}23.0 \\
1.2 \\
1.2 \\
17.9 \\
43.3\end{array}$ & $\begin{array}{r}13.2 \\
1.2 \\
0.6 \\
16.6 \\
31.6\end{array}$ \\
\hline Mining Exhaust & $\begin{array}{l}\text { Sinking } \\
\text { Water Control } \\
\text { Lining } \\
\text { Equipment } \\
\text { Subtotal }\end{array}$ & $\begin{array}{r}11.0 \\
5.8 \\
3.4 \\
0.0 \\
20.2\end{array}$ & $\begin{array}{r}14.5 \\
0.2 \\
0.6 \\
0.0 \\
15.3\end{array}$ & $\begin{array}{r}22.2 \\
1.2 \\
1.2 \\
0.0 \\
24.6\end{array}$ & $\begin{array}{r}12.6 \\
1.2 \\
0.5 \\
0.0 \\
14.3\end{array}$ \\
\hline $\begin{array}{c}\text { Waste Storage } \\
\text { Exhaust }\end{array}$ & $\begin{array}{l}\text { Sinking } \\
\text { Water Control } \\
\text { Lining } \\
\text { Equipment } \\
\text { Subtotal }\end{array}$ & $\begin{array}{r}11.2 \\
9.3 \\
5.5 \\
0.0 \\
26.0\end{array}$ & $\begin{array}{r}14.4 \\
0.3 \\
0.6 \\
0.0 \\
15.3\end{array}$ & $\begin{array}{r}22.1 \\
1.2 \\
1.2 \\
0.0 \\
24.5\end{array}$ & $\begin{array}{r}12.6 \\
1.2 \\
0.5 \\
0.0 \\
14.3\end{array}$ \\
\hline Total & & 166.7 & 123.3 & 170.3 & 115.4 \\
\hline
\end{tabular}

shown in Table 5.8. The total operational time period, including construction and decommissioning, range from year 1990 to year 2027 for salt, year 1990 to year 2026 for granite, year 1990 to year 2023 for basalt, and year 1990/to year 2026 for tuff. The construction cost headings include all facility construction, shaft development, preproduction, preoperational mining, equipment replacement, decommissioning, sealing, and surveillance costs. The operating category includes all labor, direct and indirect materials, mining during 
TABLE 5.7. Rock Logistics Sumary for Reference Cases, Millions of Tonnes

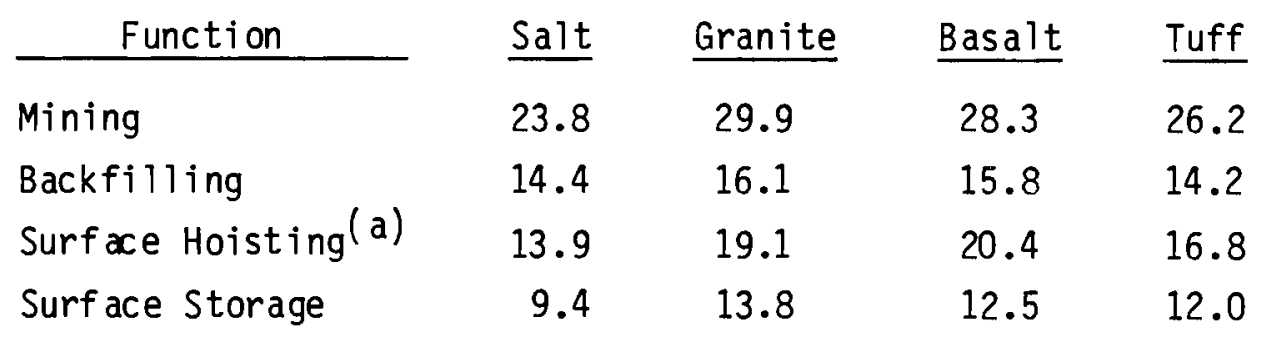

(a) Includes the following tonnages sent back down into the mine for backfilling during decommissioning:

Salt 2.25

Granite 2.7

Basalt 2.7

Shale 2.4.

operations, and utilities costs. Contingency costs in the table are distributed by cost categories based on contingency factors of $20 \%$ for construction, operations, and decommissioning. The 5-year construction period for each repository is shown from year 1990 through year 1994, with operations beginning for each repository in year 1995. Mining equipment replacement costs are assumed to occur every 8 years beginning in year 2002. All surface facility equipment costs were conservatively estimated to have a 15 -year life. Therefore, a large equipment replacement cost is shown in year 2014 for all repositories. Costs of $\$ 20.9$ million per year for 5 years are shown for constructing and equipping additional receiving and packaging modules. These modules are required to come on line in year 2005 and 2020. Since the basalt repository is filled before the year 2020, only one additional receiving and packaging module is needed. Costs shown occurring in the construction column after the operating periods have ended are for decommissioning, sealing and surveillance. Annual operating costs for the repositories range from $\$ 109 \mathrm{milli}$ on to $\$ 259$ million for salt, $\$ 133$ million to $\$ 330$ million for granite, $\$ 137$ million to $\$ 332$ million for basalt, and $\$ 124$ million to $\$ 303$ million for tuff.

\subsubsection{Unit Costs}

In this section the unit costs are analyzed for repositories in the alternative media studied. The unit costs shown here are undiscounted and 
TABLE 5.8. Cash Flow Analyses for Reference Repositories in Alternative Media, Millions of 1981 Dollars

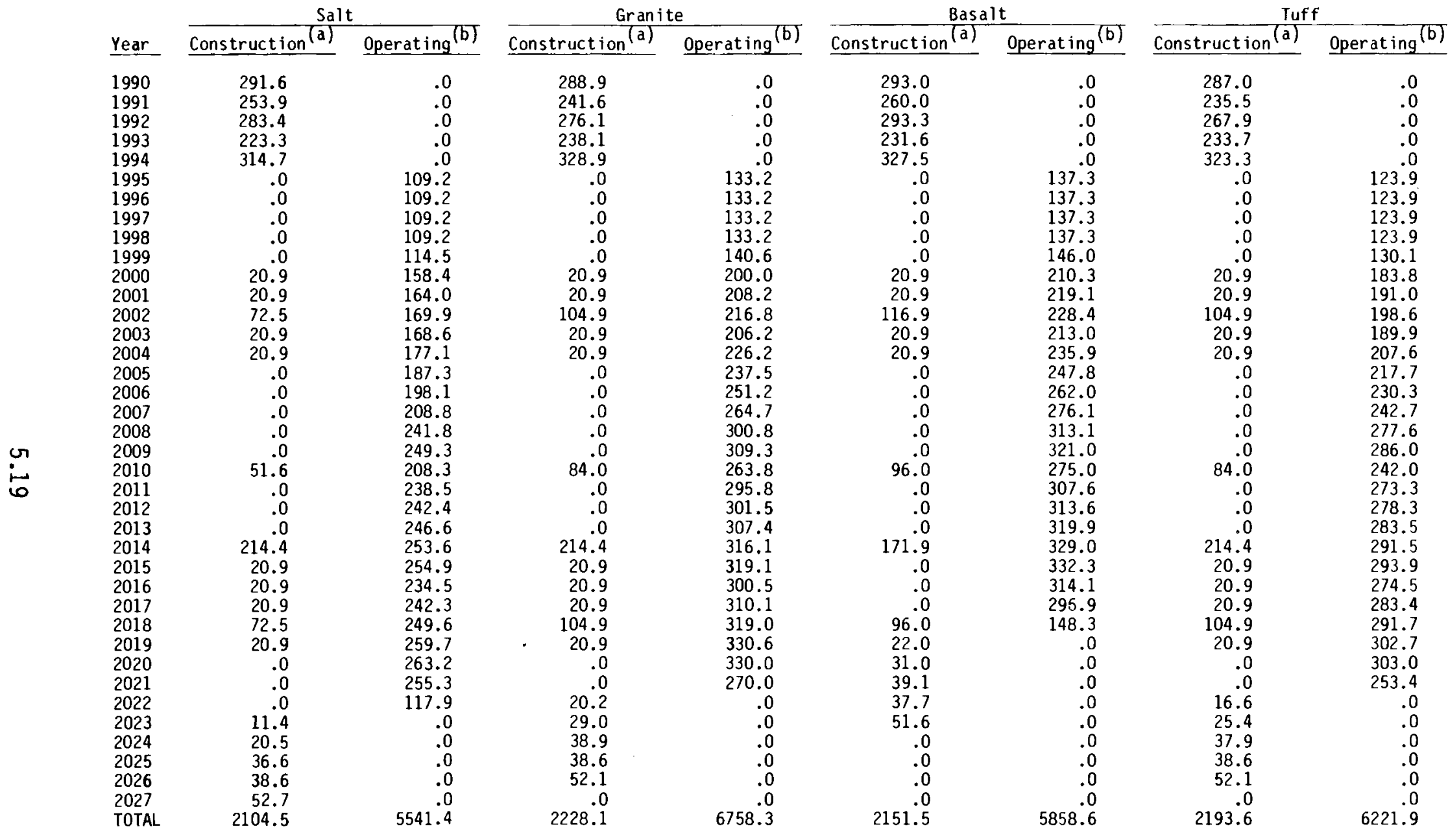

(a) Construction includes all construction, shaft development, preproduction, pre-operational mining, equipment replacement, decomissioning, sealing and surveillance costs.

(b) Operating includes all labor, direct and indirect materials, mining during operations, and utilities costs. Costs for contingencies are distribued by cost categories based on the contingency factors of 20 percent for construction, operations and decomissioning. 
unescalated and are shown in 1981 dollars. The effects of including costs of money from 0 to $7 \%$ are shown in Section 6.6. The unit costs for the reference repositories are listed in Table 5.9. The unit costs are shown subdivided into facility construction, shafts, mining, labor, packaging, hole preparation and materials, and categories not included elsewhere. Facility construction includes surface facility construction, surface facility equipment and equipment replacement, preproduction, and preoperational mining costs. The shaft category includes all shaft-related costs. Mining includes only the direct costs associated with mining the rock. Labor includes all surface and underground labor associated with waste handling and support. Packaging includes only the materials used for packaging the spent fuel. Hole preparation and

TABLE 5.9. Unit Cost Summary for Reference Repositories in Alternative Media

\begin{tabular}{|c|c|c|c|c|}
\hline \multirow[b]{2}{*}{ Category } & \multicolumn{4}{|c|}{ Repository Media } \\
\hline & $\underline{\text { Salt }}$ & Granite & Basalt & Tuff \\
\hline Facility Construction (a) & 15.50 & 16.40 & 18.20 & 16.30 \\
\hline Shafts & 2.10 & 1.60 & 2.70 & 1.50 \\
\hline Mining(b) & 3.20 & 6.50 & 8.20 & 4.60 \\
\hline Labor & 12.90 & 12.50 & 13.30 & 12.50 \\
\hline Packaging & 20.60 & 20.60 & 20.60 & 20.60 \\
\hline $\begin{array}{l}\text { Hole Preparation and } \\
\text { Materials }\end{array}$ & 10.00 & 20.40 & 21.00 & 17.00 \\
\hline Other $(c)$ & 17.70 & 20.20 & 23.00 & 19.40 \\
\hline TOTALS & 82.00 & 98.20 & 107.00 & 91.90 \\
\hline
\end{tabular}

(a) Facility construction includes surface facility construction, surface facility equipment and equipment replacement, preproduction, and reoperational mining costs.

(b) Mining includes only the direct mining costs during repository operation.

(c) Other includes backfilling, rock hoisting, surface storage, mining and underground waste handling equipment replacement, decommissioning, shaft sealing and surveillance costs. 
materials includes hole drilling, sleeve placement, sleeve materials, and bentonite costs. The "other" category includes backfilling, rock hoisting, surface storage, mining and underground waste handling equipment replacement, decommissioning, shaft sealing, and surveillance costs.

Since unit costs take into account the amount of waste emplaced in the repository as well as total repository costs, these costs are used as the bas is for all subsequent repository cost comparisons. As shown in Table 5.9 the salt repository has the lowest cost of all the media studied. The cost of the tuff repository is about $10 \%$ higher; the cost of the granite repository $20 \%$ higher, and the cost of the basalt repository $30 \%$ higher than that of salt. The cost differences between the salt and the granite or basalt repositories appear large enough to represent a real cost advantage for salt. The cost difference between the tuff and basalt repository probably also represents a real cost advantage. The most significant cost difference among media is due to the difference in hole drilling costs, which are included in the hole-preparationmaterials category. Other significant cost differences exist in direct mining costs and in the mining equipment replacement cost, which is shown in the "other" category. Facility construction and labor costs are somewhat higher for the basalt repository because these costs are charged against a smaller amount of fuel than that emplaced in the other repositories, as explained in the total costs section. The unit costs for shaft construction vary significantly among media; however, the cost differences do not contribute significantly to the overall differences.

Please note again that the reference repositories are not optimized and include uncertainties in cost data. The cost differences shown here will change as designs in each media are optimized and as better media-specific data are generated. For example, higher thermal loading limits in the hard rock cases would reduce the cost differences shown above. 
.

. 


\subsection{SENSITIVITY ANALYSES}

In this section the results of sensitivity analyses performed to investigate the effects on costs of changing cost and media sensitive variables in alternative media are discussed. To more clearly understand these effects, on ly one independent parameter was varied at a time. Variables that were not independent of the varied parameter were adjusted so that the ir values reflected the change in the independent parameter. For example, increasing or decreasing the number of rows per room required that room widths be adjusted accord ing ly.

These sensivity analyses identified trends that aided in selecting the combinations of variables that would produce minimum-cost scenarios. This analysis is explained in Subsection 6.7 .

\subsection{PACKAGE VARIATION}

This section analyzes the effect of various package designs on unit costs. Since recent NRC guidelines have proposed requiring a package that will mainta in its integrity for 1000 years, the cost effect of requiring these packages was examined. The effect of increasing fuel loading per package was also addressed.

Three types of packages were identified for analysis. The first two designs are 1000-year borehole package designs; the last is not. The first type of package is the reference package described in Section 5.2.2 of this report. This package basically consists of a carbon steel container with a $1 / 4$ in. titanium skin. The package is designed to contain three disassembled PWR elements or 8 disassembled BWR assemblies in a single unit. The second package design is similar to the reference package, but holds complete assemblies. As such it will contain only one PWR or two BWR assemblies. The third design is a simple package design consisting of a carbon steel container holding one PWR or two BWR elements. All packages are assumed to be placed in carbon steel sleeves installed vertically in the room floor; however, the multibarrier package designs using the titanium canisters also have a 
$0.3 \mathrm{~m}$ annulus of preformed bentonite blocks around the sleeves. A cost comparison for these three packages for each of the alternative media is shown in Figure 6.1. Each group of bar graphs in the figure compares the package costs for each type of repository. The figure shows that repository costs are almost doubled if 1000-year packages are used, unless the amount of fuel per package is increased by disassembling the fuel elements. However, if fuel assemblies

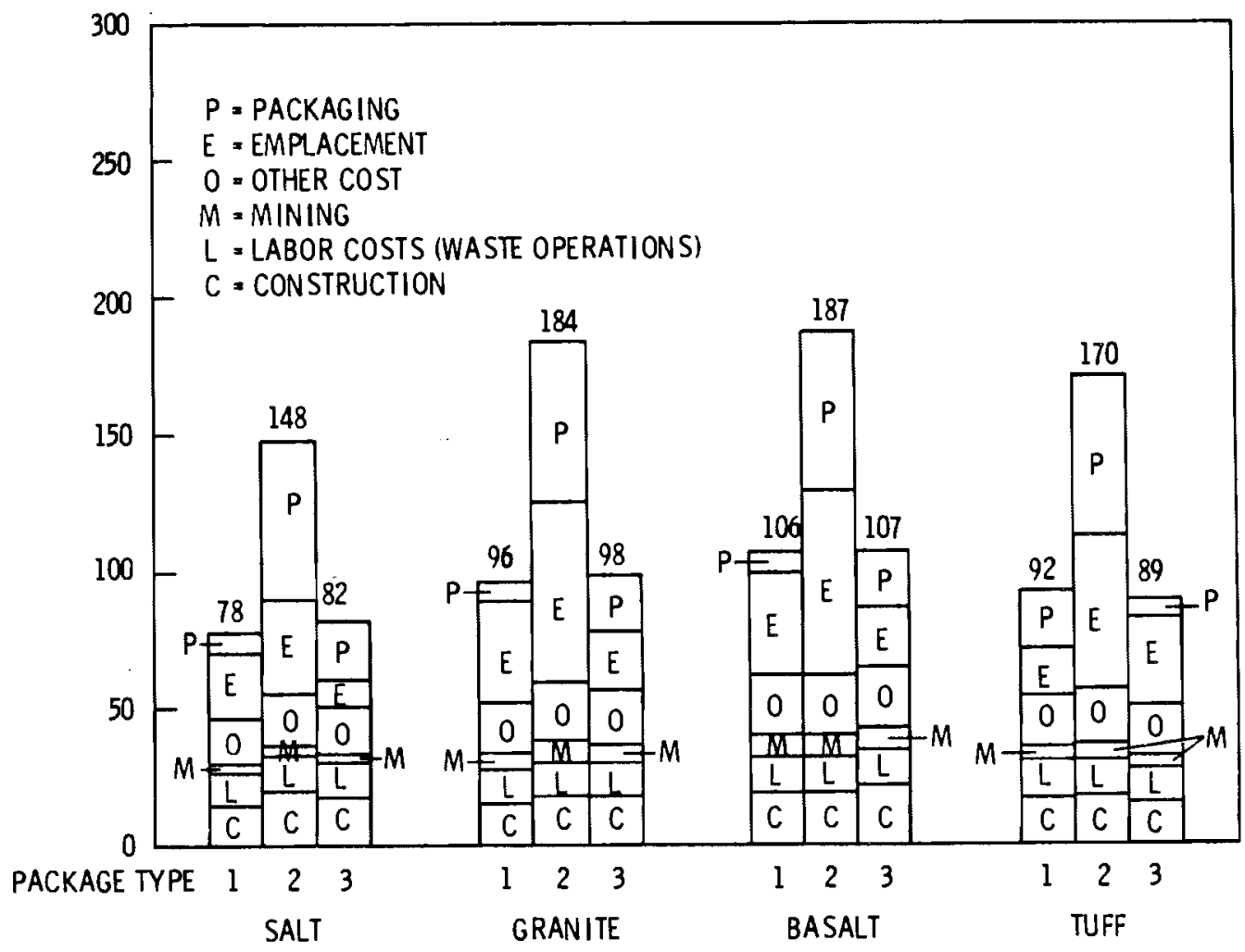

Package Type

$1=1$ PWR or 2 BWR in carbon steel package emplaced with carbon steel sleeve.

$2=1$ PWR or 2 BWR in titanium-carbon steel package emplaced with carbon steel sleeve surrounded by bentonite.

$3=3$ PWR or 8 BWR disassembled and packaged in titanium-carbon stee 1 package emplaced with carbon steel sleeve surrounded by bentonite.

FIGURE 6.1. The Effect of Packaging Concept on Unit Repository Costs in Alternative Media 
are disassembled as assumed in the reference case, the repository costs would be only slightly higher than those for the simple carbon steel package case.

The bar graphs in the figure are subdivided into the various elements making up the unit costs. For the simple carbon steel packages shown as package type No. 1 in the figure, emplacement costs account for the largest percentage of the cost breakdown due to the large number of holes that must be drilled. Labor, construction and other costs (see definition in Section 5.3.3) also account for a significant portion of the total costs. Packaging and mining costs are minor. For the 1000-year packages with one PWR or two BWR elements per package, the packaging and emplacement costs dominate all other costs. This effect is especially pronounced in the harder rock media because of the ir higher hole-drilling costs.

For the 1000-year packages with disassembled fuel elements holding three PWR or eight BWR assemblies, the packaging and emplacement costs are greatly reduced from the nondisassembled package, but still account for a very significant portion of total repository costs. Construction, labor, mining and other costs vary slightly with package types but not significantly.

When results for different repository media are compared, salt repositories clearly have a significant cost advantage over other media if 1000-year packages are used and the spent fuel assemblies are not disassembled. If simple packages are used or if the spent fuel is disassembled, the cost advantage for salt is greatly reduced.

\subsection{THERMALLY LIMITING VARIABLES}

In th is section the cost sensitivity of minimum hole pitch, nearfield thermal loading and very-near-field temperature limitations for basalt is discussed. The effect of minimum hole pitch on costs is shown in Figure 6.2 for the single PWR multibarrier package. Minimum hole pitches as used in this section refer to the structurally limited hole pitches. According to Kaiser (1980), normal mining practice limits the web distance (the distance from the edge of one hole to the edge of the other) to a distance approximately equal 


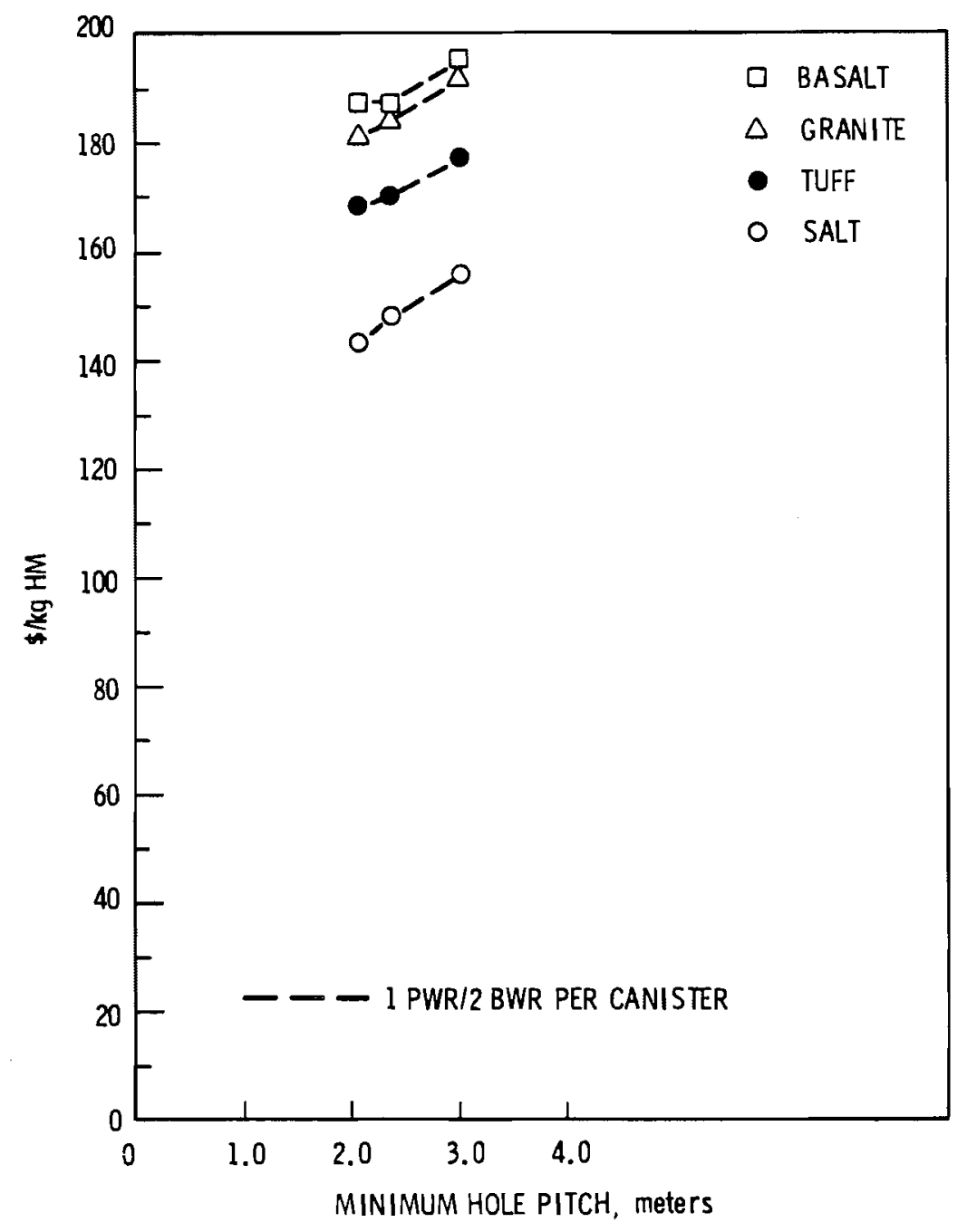

FIGURE 6.2. The Effect of Minimum Hole Pitch (Structurally Limited)

to the hole diameter. Since this distance is uncertain, the effect of using three fourths of the hole diameter or 1-1/2 times the hole diameter as a minimum pitch was investigated. Because of the high heat loading of the reference packages, and the limiting repository thermal criteria, the spacing of these packages is always at distances significantly greater than the structurally limiting hole pitches; therefore, these packages are not shown in Figure 6.2. The plot shows a cost increase of 6 to $8 \%$ when minimum hole pitches are increased from 2 to $3 \mathrm{~m}$. The graph shows also that costs are not reduced for 
minimum hole pitches that are less than $2.4 \mathrm{~m}$ in basalt because very-near-field temperature limitations prevent the spacing of spent fuel any closer than this distance.

The effect of near-field thermal loading on cost is shown in Figure 6.3. The results show that costs are quite sensitive to near-field loadings since they decrease $\sim 20 \%$ as near-field loadings are increased from $30 \mathrm{~kW}$ per acre to $60 \mathrm{~kW}$ per acre. Costs decrease with increased thermal loading because centerline distances between canisters (pitches) are decreased as thermal loading

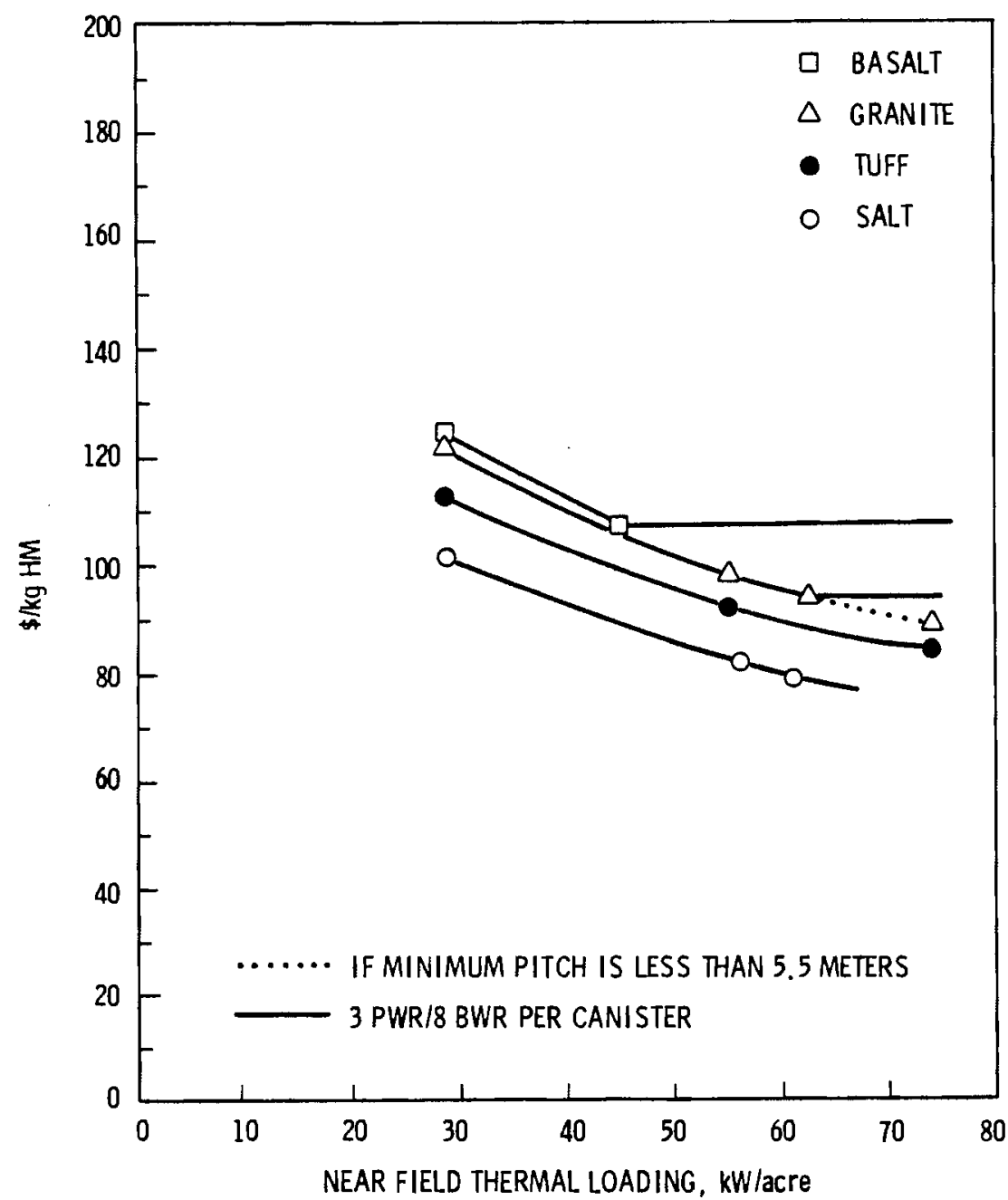

FIGURE 6.3. The Effect of Near-Field Thermal Loading on Unit Repository Costs 
limits are increased. More spent fuel therefore is allowed to be emplaced per acre, bringing the unit cost of the repository down. This conclusion is true for all media except basalt. The figure shows that repository costs in basalt decrease with increases in near-field loading up to $\sim 45 \mathrm{~kW}$ per acre due to decreasing centerline distances. Near-field thermal loading cannot be increased past this point without increasing extraction ratios because the pitch is limited by very-near-field temperature limitations. Thus, the verynear-field criteria instead of the near-field heat criteria become limiting. At $\sim 62 \mathrm{~kW}$ per acre, the estimated limiting pitch of $5.5 \mathrm{~m}$ in granite is reached. Since this estimate is based on very conservative assumptions, costs were calculated assuming that this limiting pitch was reduced to $4 \mathrm{~m}$. This cost reduction is shown by the dotted line for granite.

The near-field loadings shown in the graph are all within limits proposed for these media and as explained in Section 5.2.7. A near-field thermal loading of $\sim 65 \mathrm{~kW}$ per acre in salt results in a far-field loading of $\sim 60 \mathrm{~kW}$ per acre since the heat is averaged over a larger area. For this reason, the graph shows the cost reduction in salt out to a near-field thermal loading of $\sim 65 \mathrm{~kW}$ per acre.

The minimum pitch between canisters for the basalt repository is based on a $200^{\circ} \mathrm{C}$ temperature limit in basalt and a $300^{\circ} \mathrm{C}$ spent fuel cladding temperature limit, as explained in Section 5.2.7. However, some evidence indicates that the cladding temperature limit could be increased to $400^{\circ} \mathrm{C}$ (Einziger et a 1. 1981). The limiting media temperature of $200^{\circ} \mathrm{C}$ also is uncertain because the basalt rock itse if is capable of withstanding much higher temperatures. Because of these uncertainties, the cost effect of increasing minimum medium temperature to $300^{\circ} \mathrm{C}$ was analyzed (this would result in approximately a $400^{\circ} \mathrm{C}$ canister centerline temperature). This analysis shows that under these conditions, emplacement in basalt would be near-field limited instead of very-nearfield limited. The cost reductions would be $\$ 7 \mathrm{~kg} \mathrm{HM}$ heavy metal or $7 \%$ from the reference case.

The last item studied in this section was the cost effect of using the same emplacement density for BWR fuel as for PWR fuel. This results in a cost 
penalty for the repository because the BWR canisters have a significantly lower heat output than PWR canisters $(1.36 \mathrm{~kW} / \mathrm{can}$ ister vs. $1.65 / \mathrm{kW} / \mathrm{can}$ ister, respectively, assuming 3 PWR and 8 BWR assemblies per canister). The results of this analysis show a cost increase of $2 \$ 5 / \mathrm{kg} \mathrm{HM}$ or $5 \%$ due to a reduction in repository capacity of $\sim 10 \%$.

\subsection{MULTI -BARRIER CONSIDERATIONS}

In this section the cost effects of varying bentonite backfill diameters, package dimensions, and hole liners are discussed.

The effect of varying bentonite backfill diameter on costs is shown in Figure 6.4 for the single-PWR-titanium package. Using a $0.3 \mathrm{~m}$ radius of bentonite around the canister will increase repository costs by 215 to $25 \%$. Costs increase because of larger quantities of bentonite required and higher hole drilling costs. For the reference package design, cost increases are much less ( $\sim 5$ to 11\%) because the number of holes required is reduced by $67 \%$. The costs increase more rapidly for repositories in the harder rock media (as bentonite radii increase) than they do for salt because of the higher unit hole drilling costs in the hard rock media.

Figure 6.5 shows the effect of increasing package diameter on unit costs. For the single-PWR-titanium package, costs increase very rapidly with increases in diameter. For example, in salt an increase in diameter of $20 \%$ would result in a $20 \%$ increase in total repository costs. Cost increases are much less dramatic for the reference package since significantly fewer packages are required, as explained earlier.

The effect of package length on unit costs is analyzed in Figure 6.6. Because of time limitations, only the single-PWR-titanium-canister case was evaluated. The analysis shows that repository costs are reduced significantly by reducing the canister length. This effect favors disassembly of canisters because canister length can be decreased by removing the end fittings of the spent fuel assemblies. 


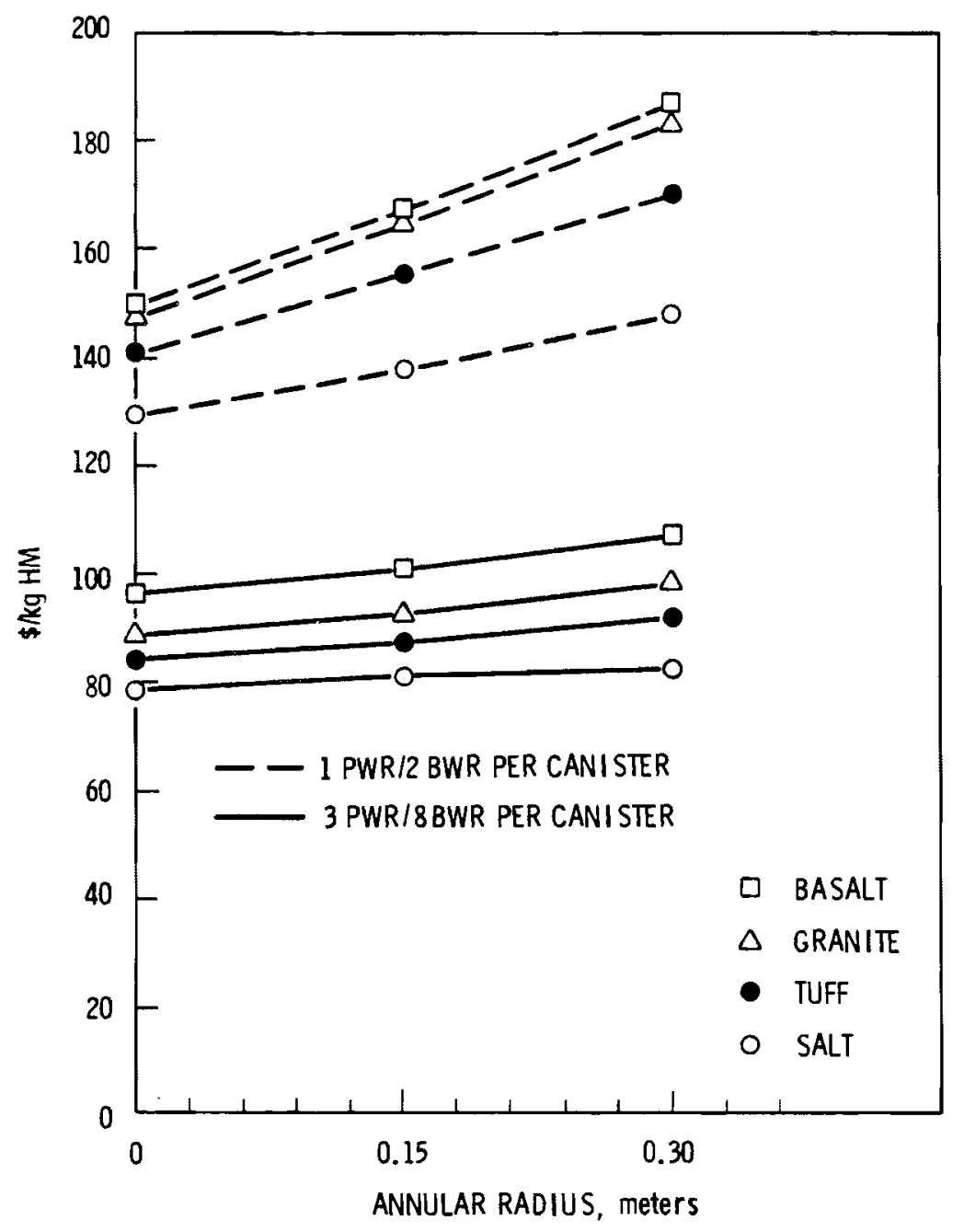

FIGURE 6.4. The Effect of Bentonite Backfill Annular Radius on Unit Costs

The effect of hole liner assumptions on repository costs was investigated by examining cost reductions if no hole liner were used and cost increases if very expensive inconel liners were used. Removing the hole liner would decrease costs by $\sim \$ 24 / \mathrm{kg}$ HM or 15 to $20 \%$ for the single PWR titanium package and $\$ 7 / \mathrm{kgHM}$ or $7 \%$ for the reference package. Using $1-$ in. thick inconel liners would increase costs for the reference package by $\$ 54$ to $\$ 60$ per $\mathrm{kg} H M$ or 55 to $60 \%$ [incone 1 liner costs of $\$ 70,000$ each are based on JAI-173 (E. R. Johnson Associates, Inc. 1981) estimates escalated to 1981 dollars]. 


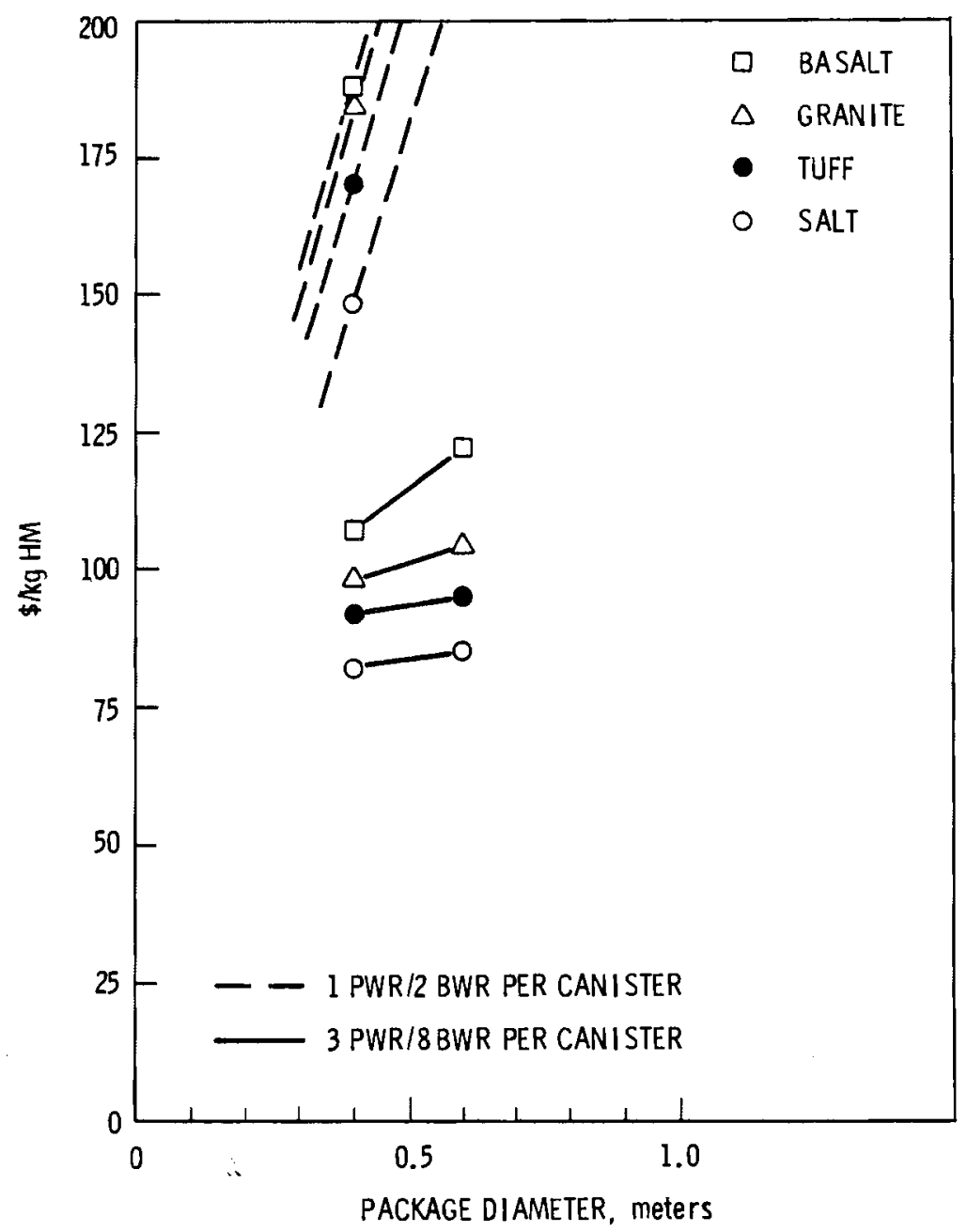

FIGURE 6.5. The Effect of Package Diameter on Unit Costs

\subsection{UNDERGROUND DESIGN CONSIDERATIONS}

In this section the effect of extraction ratio, number of rows per room and repository size on unit costs is discussed. The extraction ratio cost sensitivity is shown in Figure 6.7. The illustration shows that costs do not change markedly with increasing extraction ratio for most of the media because emplacement is limited by near-field thermal criteria and increasing the extraction ratio simply results in increasing the pitch between canisters. 


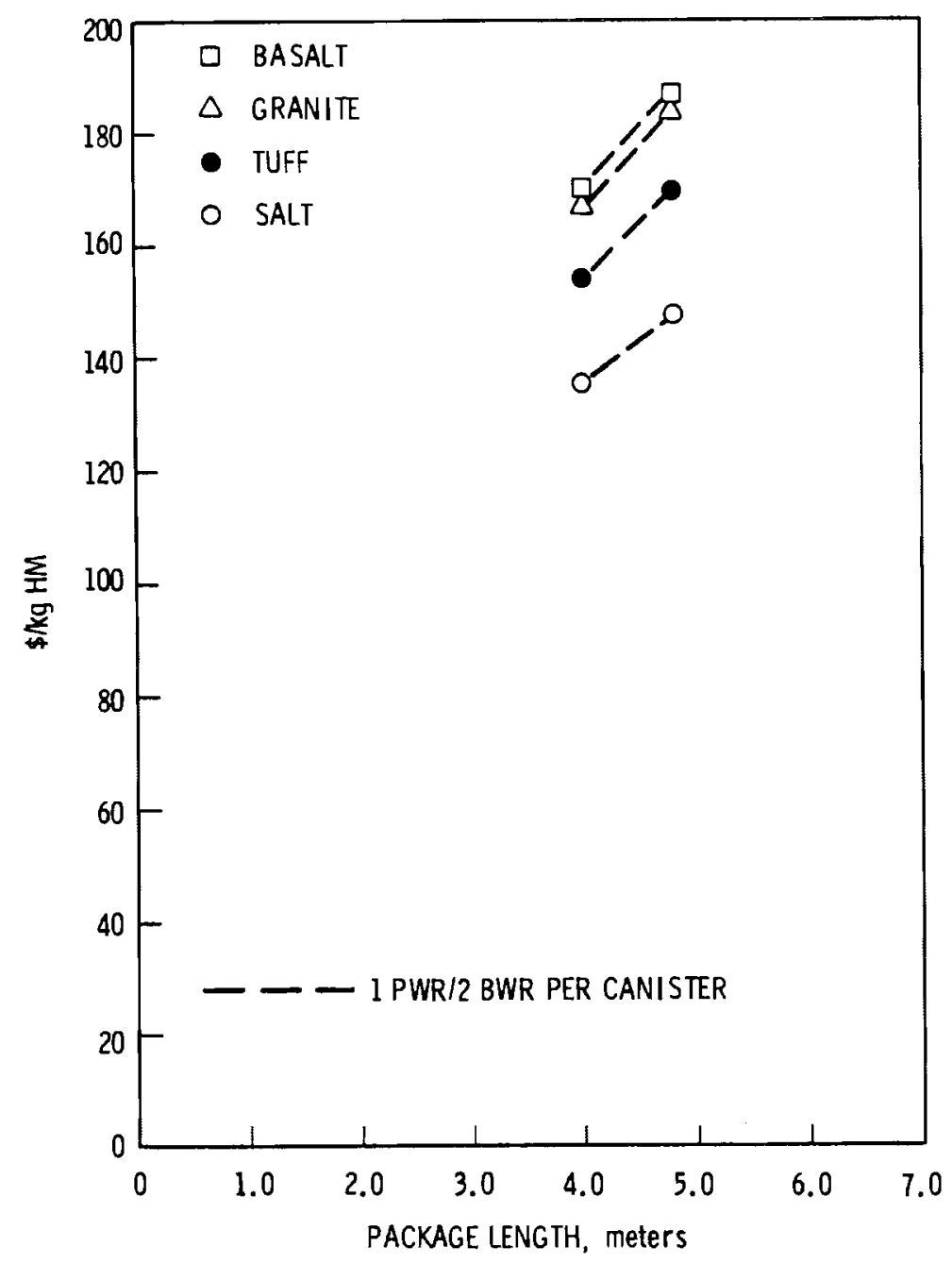

FIGURE 6.6. The Effect of Package Length on Unit Costs

For the single-PWR-titanium canisters, costs decrease slightly for extraction ratios from 20 to $30 \%$ in the hard rock media. However, the costs then increase at higher extraction ratios because increases in mining costs per kilogram as a result of the emplacement of additional canisters are greater than decreases in unit fixed costs. This effect is examined in more detail in Subsection 6.7. The basalt repository costs for this case increase somewhat faster than the granite repository costs because the BWR fuel placement is pitch limited and therefore pitches between this waste type cannot be decreased as extraction ratios are increased. For the salt medium, emplacement of single-PWR-titanium 


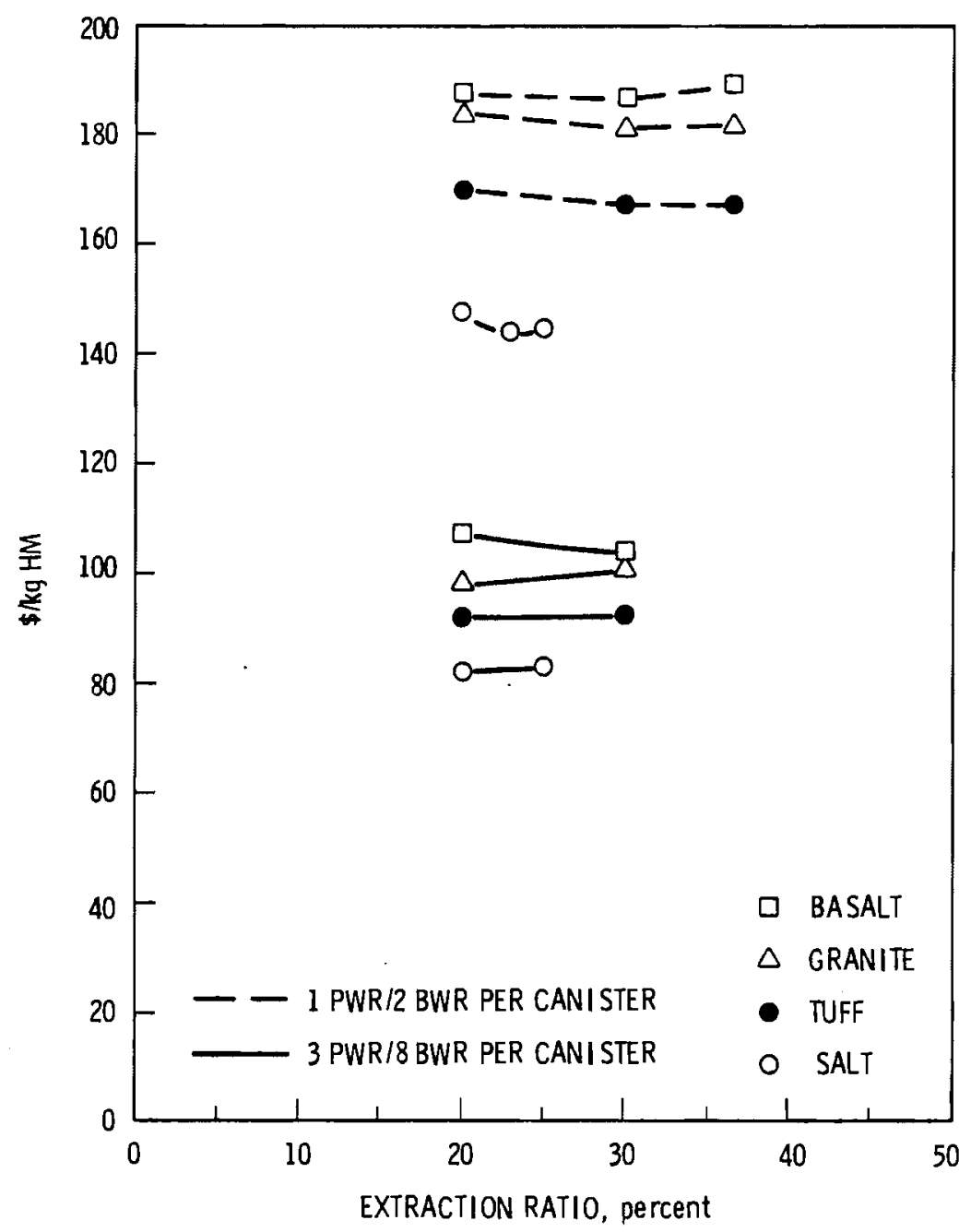

FIGURE 6.7. The Effect of Extraction Ratio on Unit Repository Costs

canisters is still limited by minimum pitches between canisters instead of near-field criteria. Thus, increasing extraction ratios from 20 to $25 \%$ results in a steeper cost reduction than for the harder rock media. For the reference case packages, costs for granite, tuff, and salt repositories increase as extraction ratios are increased since they are near-field heat limited at a $20 \%$ extraction ratio, and increasing the extraction ratio increases mining costs substantially with only a small increase in the number of assemblies emplaced in the repository. 
The effect of changing the number of rows per room on unit repository costs is shown in Figure 6.8. For the single-PWR-titanium canister, increasing the number of rows per room from 2 to 3 has very little impact on granite and tuff repository costs and results in a small decrease in salt repository costs. The costs for salt, granite and tuff do not change significantly since the number of canisters emplaced per acre is almost the same whether two or three rows per room are used (ratio of rows per room to room width is about

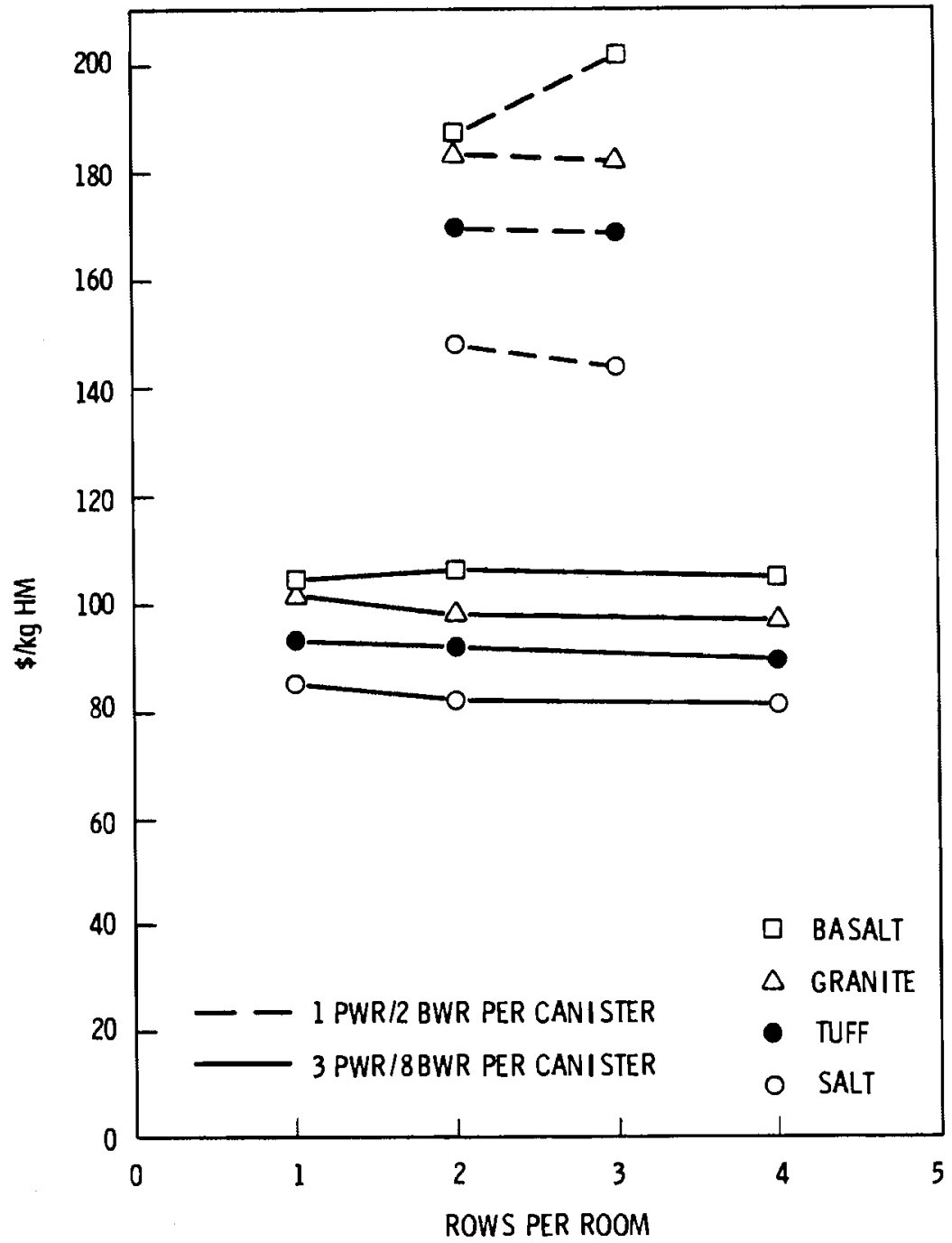

FIGURE 6.8. The Effect of Number of Rows Per Room on Un it Repository Costs 
the same). For the single-PWR-titanium canister in the basalt repository, costs increase substantially when going from two to three rows per room. Again, costs increase because emplacement in the basalt repository is limited by very-near-field criteria and putting three rows in a room requires increasing the pitch between canisters to stay with in minimum temperature guidelines. For the reference packages, costs decreased somewhat in going from one to two rows per room for the granite and salt media, but decreased only slightly in going from two to four rows per room. Slight cost reductions are also shown for the tuff repository. The cost decreases in these media occur because canister emplacement in these repositories is limited by the minimum pitch between canisters for the one-row-per-room case, but is limited by the nearfield thermal loading for the two- and four-rows-per-room cases. For the basalt repository, emplacement is pitch limited for one, two, and four rows per room because of the very-near-field thermal criteria. Based on the changes in pitches developed for multiple rows per room using these thermal criteria, two rows per room cost slightly more than either one or four rows per room.

The above analyses postulate that widening rooms to accept additional rows per room is feasible. Whether this can be accomplished depends on the rock conditions and depth and therefore may not be possible. In any case, the cost reductions appear to be small.

The effect of repository size on unit costs was estimated using 1200- and 3000 -acre repositories. In making this estimate, ma in corridor lengths, pane 1 lengths and ventilation requirements were increased; however, the effect of traveling longer distances on repository receiving capacity was not included. The results of the analysis are shown in Figure 6.9. Decreasing repository size from 2000 acres to 1200 acres increases costs from 12 to $14 \%$, and increasing repository size from 2000 to 3000 acres decreases the repository costs from 8 to $10 \%$. These ratios of cost increases and reductions are approximately the same for all media. As a point of interest, the table shows that costs for a small 1200-acre repository in salt, such as one in domed salt, would be approximately the same as costs for a 2000-acre repository in tuff or costs for a 3000 -acre repository in granite. 


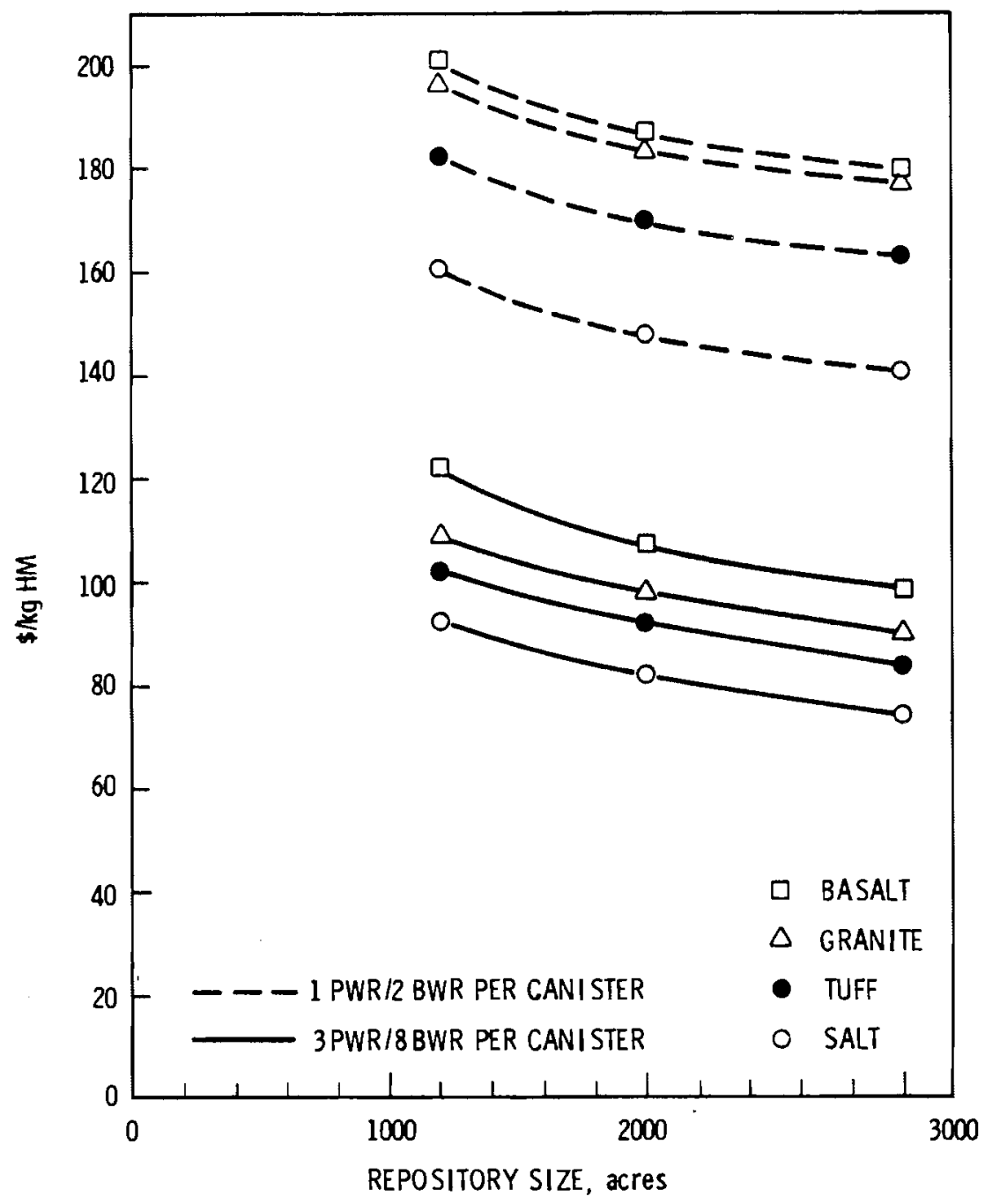

FIGURE 6.9. The Effect of Repository Size on Unit Costs

\subsection{SELECTED OPERATING COST DATA SENSITIVITY}

In this section the cost sensitivity of the program's input cost data that are media-sensitive is analyzed. The two parameters chosen for analys is are mining costs and hole drilling costs.

Figure 6.10 shows the effect of changes in unit mining and rock handing costs on total repository unit costs. The figure shows that total repository costs are not very sensitive to the unit mining and rock handling costs. For example, doubling the mining, backfilling and rock handling costs only results 


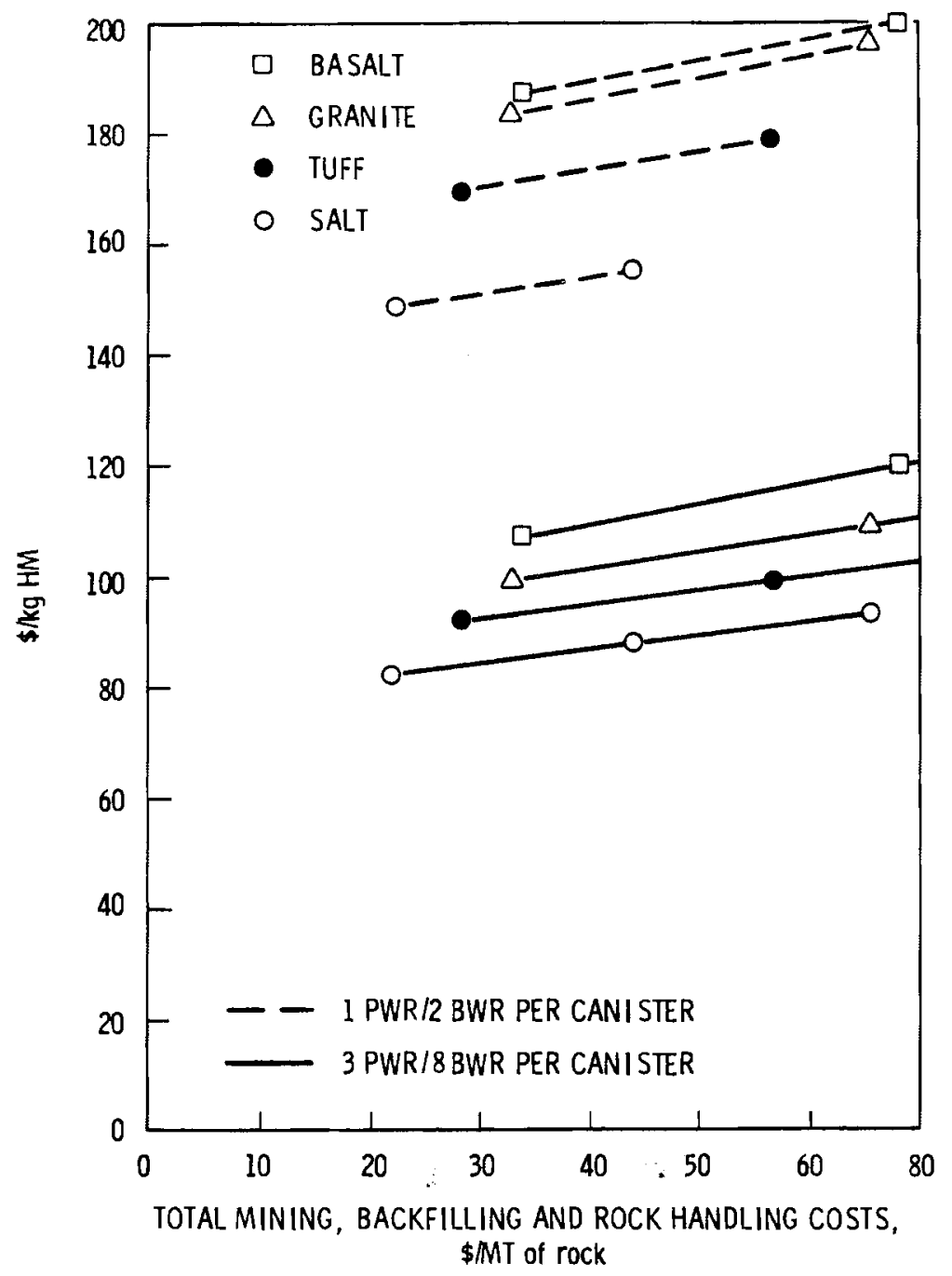

FIGURE 6.10. The Effect of Unit Mining and Rock Handling Costs on Unit Repository Costs

in a 10 to $12 \%$ increase in tota 1 repository costs for the reference package case. For the basalt and other hard rock media repositories, the slopes of the lines are slightly higher, reflecting the differences in cost per tonne mined for the hard versus the soft media.

Figure 6.11 shows the effect of the unit hole excavation costs on total repository unit costs. For the one-PWR-titanium-canister case, the slope of the lines indicates a substantial increase in total costs as unit excavation costs increase. This slope is much less marked for the three-PWR-reference 


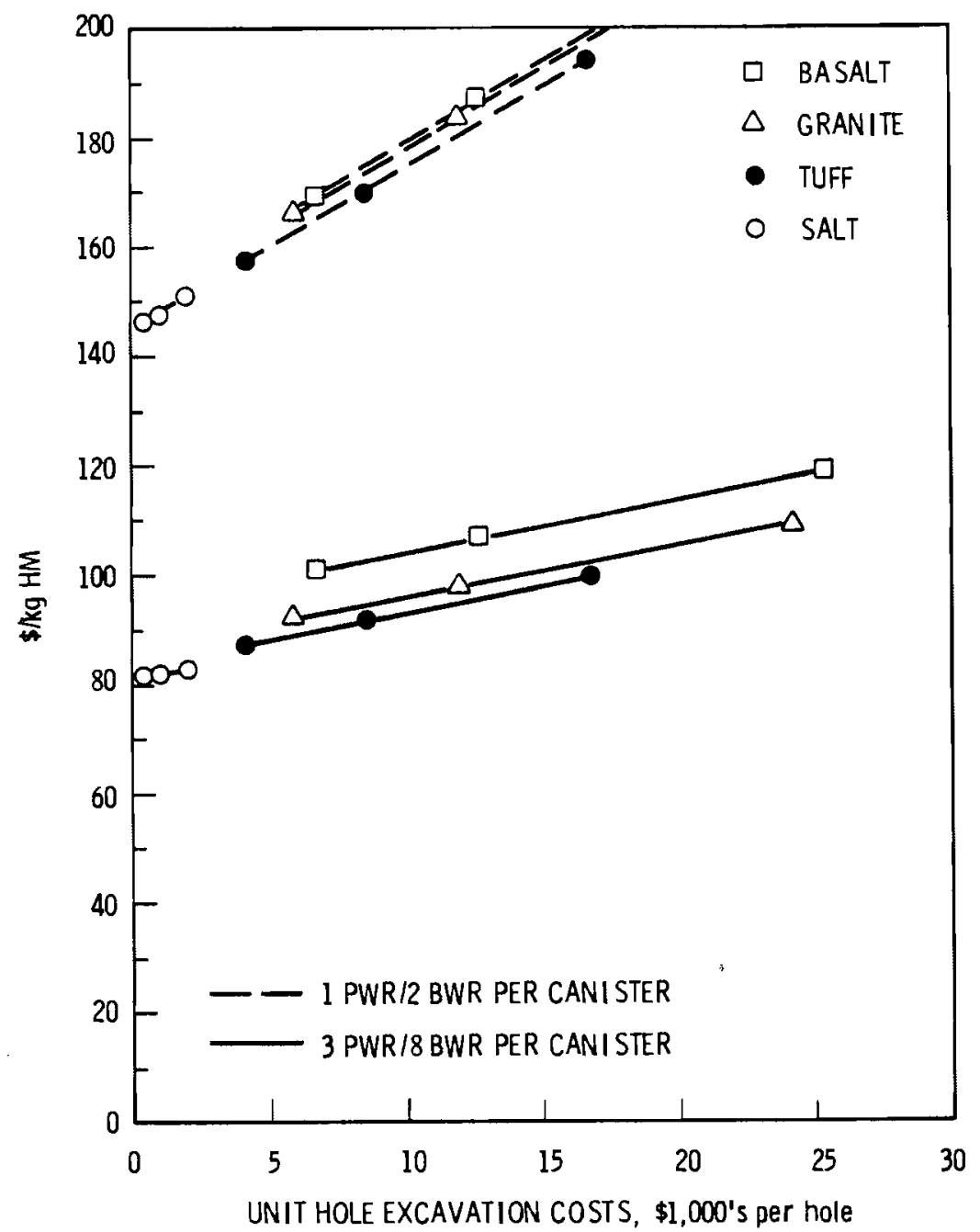

FIGURE 6.11. The Effect of Unit Hole Excavation Costs on Unit Repository Costs

package case because fewer packages are emplaced and fewer holes are required. Changes in hole-drilling costs for salt repositories do not significantly affect the total repository costs. However, increasing the unit hole excavation costs from $\$ 5000$ to $\$ 10,000$ per hole increases unit repository costs about $6 \%$ in hard rock media.

\subsection{COST OF FUNDS}

The effect of including the cost of government funds on repository costs is shown in this section. This effect for both the single-PWR-titanium 
canister case and the reference package case is illustrated in Figure 6.12. This illustration shows that repository costs increase substantially as the cost of money increases. For a cost of money of $7 \%$, repository costs increase 225\%. Note that a 11 cost estimates in this report are stated in terms of constant dollars and that the cost of money used, therefore, should be an uninflated cost of money. Thus, based on uninflated historical rates, interest rates from 1 to $3 \%$ would probably be most appropriate for this analysis.

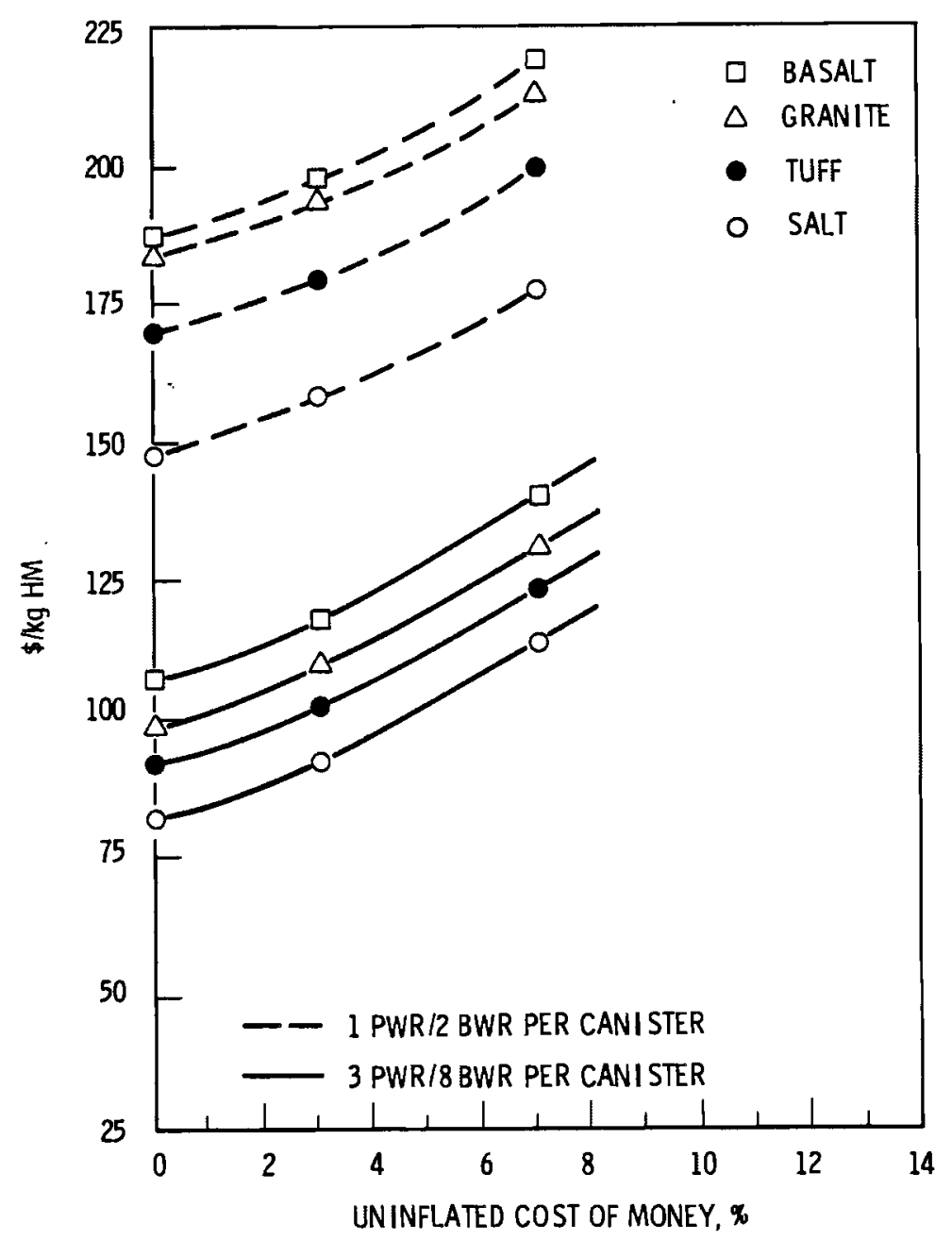

FIGURE 6.12. The Effect of Cost of Money on Unit Costs 


\subsection{COMBINED PARAMETRIC EFFECTS}

In this section the results of an analysis that used combinations of parameters analyzed individually in the previous sections are presented. Based on the previous analyses, repository costs would be reduced by using large repositories, designing a package to minimize diameter and length while maximizing the amount of spent fuel per package (such as the disassembled package described in the reference case), maximizing near-field thermal loading based on current criteria, and tailoring emplacement density based on heat loading for each waste type. This analys is examines maximum thermal loading, emplacement configurations and extraction ratio to determine minimum cost combinations. The analys is assumes a near-field thermal limit of $80 \mathrm{~kW}$ per acre for the hard rock media and a far-field thermal limit of $60 \mathrm{~kW}$ per acre for salt. Other basic assumptions are the same as those used for the reference case (except, of course, for the extraction ratio and the emplacement configuration). The results for a case assuming four rows per room are shown in Figure 6.13 , which plots extraction ratios as a function of repository cost. For a salt repository, the figure shows that minimum costs are achieved with extraction ratios from 20 to $25 \%$. Minimum costs are achieved at extraction ratios of $20 \%, 25 \%$, and $40 \%$ for tuff, granite, and basalt repositories, respectively. Analyses of costs for one row per room show costs $\sim \$ 2 / \mathrm{kg} \mathrm{HM}$ higher than for the four-row-per-room cases for salt, granite and tuff, and 几\$6/kg higher for basalt (not plotted on the graph).

The cost minimums shown in Figure 6.13 occur because of the opposing cost effects caused by increasing the number of spent fuel assemblies in the repository versus increasing the rock mined to emplace the spent fuel assemblies. As more spent fuel assemblies are emplaced per repository, the fixed costs per assembly decline, reducing the overall repository unit costs. However, since the canister emplacement densities in the repositories are heat limited, mining costs per unit of fuel emplaced begin increasing and drive the unit repository cost upward. These opposing effects are illustrated in Figures 6.14 and 6.15 for further clarity. Figure 6.14 shows repository capacity in terms of spent fue 1 assemblies emplaced in 2000-acre repositories as a function of extraction ratio. At low extraction ratios, canister emplacement densities 


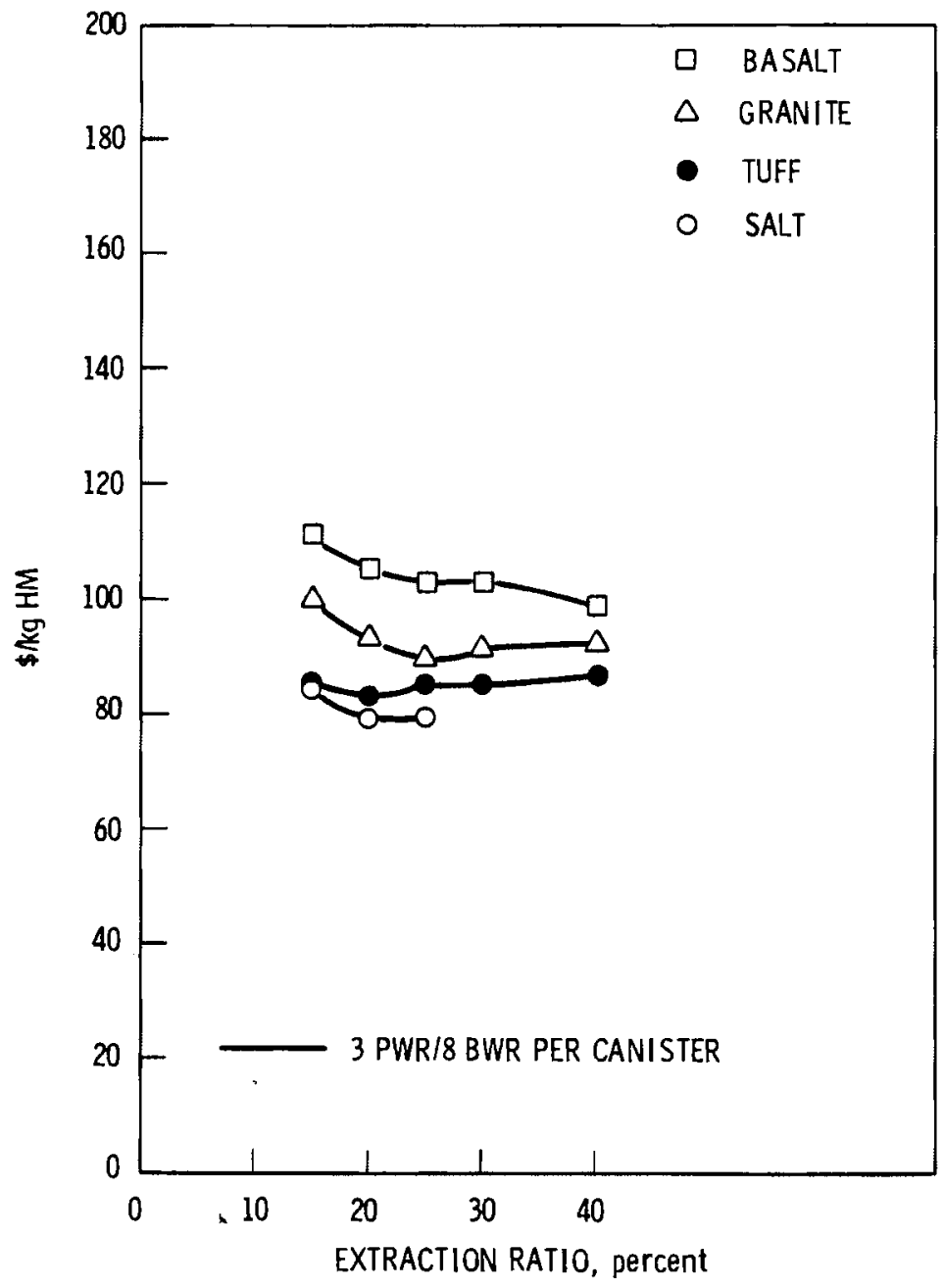

FIGURE 6.13. Optimization Scenarios (4 rows per room, $60 \mathrm{kw} / \mathrm{acre}$ far-field limit in salt, $80 \mathrm{kw} /$ acre near-field limit in other media)

are limited by the minimum pitch between canisters. Thus, as extraction ratios are increased, more canisters per acre can be emplaced without increasing canister pitch. This results in large increases in total spent fuel assemblies emplaced as extraction ratios are increased from 15 to $20 \%$. However, at 20\% near-field thermal criteria become limiting for the tuff and salt repositories and thereby cause the slopes of these curves to level off. At a $25 \%$ extraction ratio, the near-field thermal criteria become limiting for the granite repository. For the basalt repository, canister emplacement is 


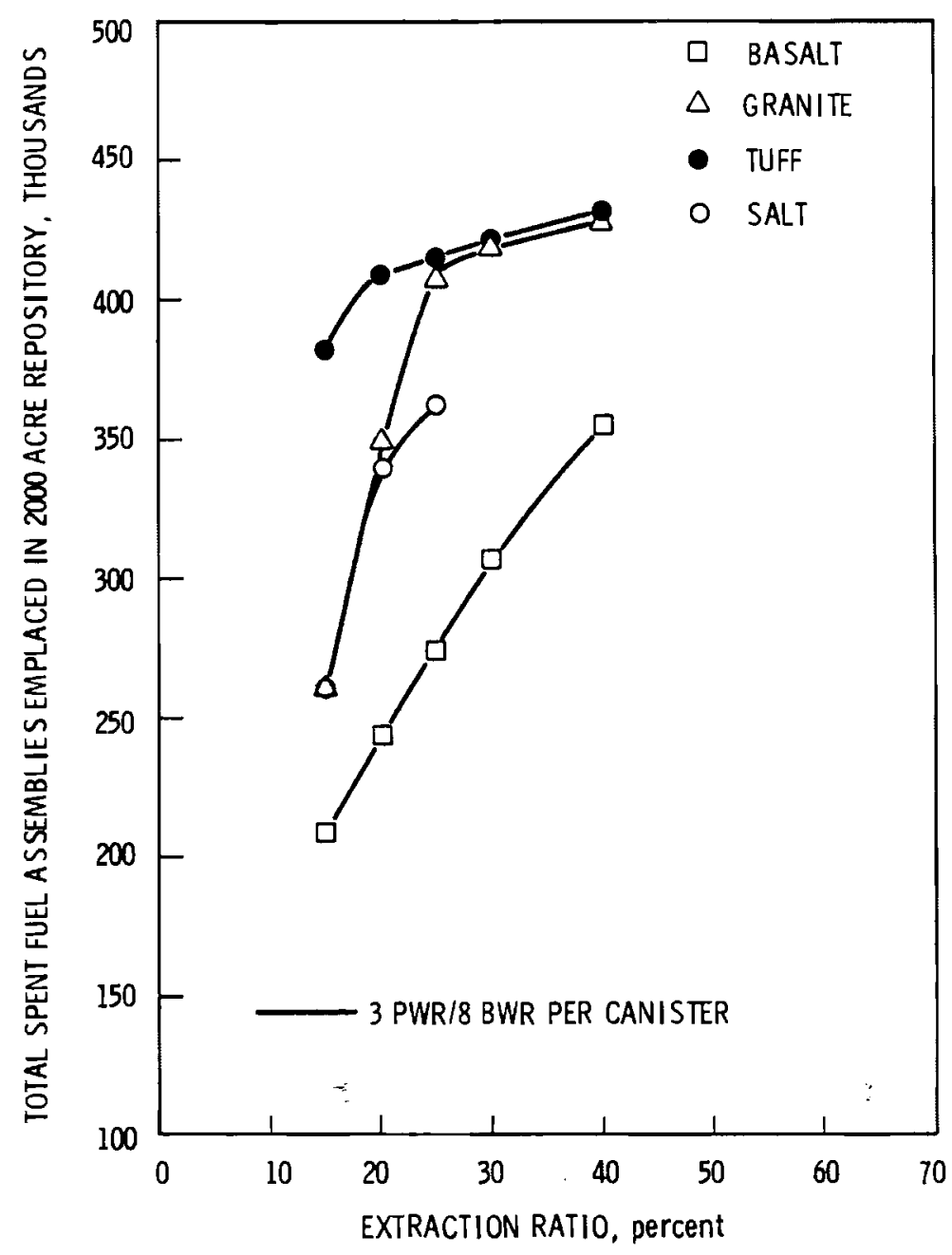

FIGURE 6.14. The Effect of Extraction Ratio on Repository Capacity Using Four Rows Per Room

very-near-field limited over the entire range (15 to 40\%) of extraction ratios (that is, as extraction ratios increase, pitches between canisters must also increase). The repository capacity in basalt does not increase as rapidly with increasing extraction ratio as it does in the other media. However, it continues to increase significantly over the entire 15 to $40 \%$ range evaluated.

Figure 6.15 shows the effect of rock mined in terms of tonnes per spent fuel assembly as a function of extraction ratio. For salt and granite 


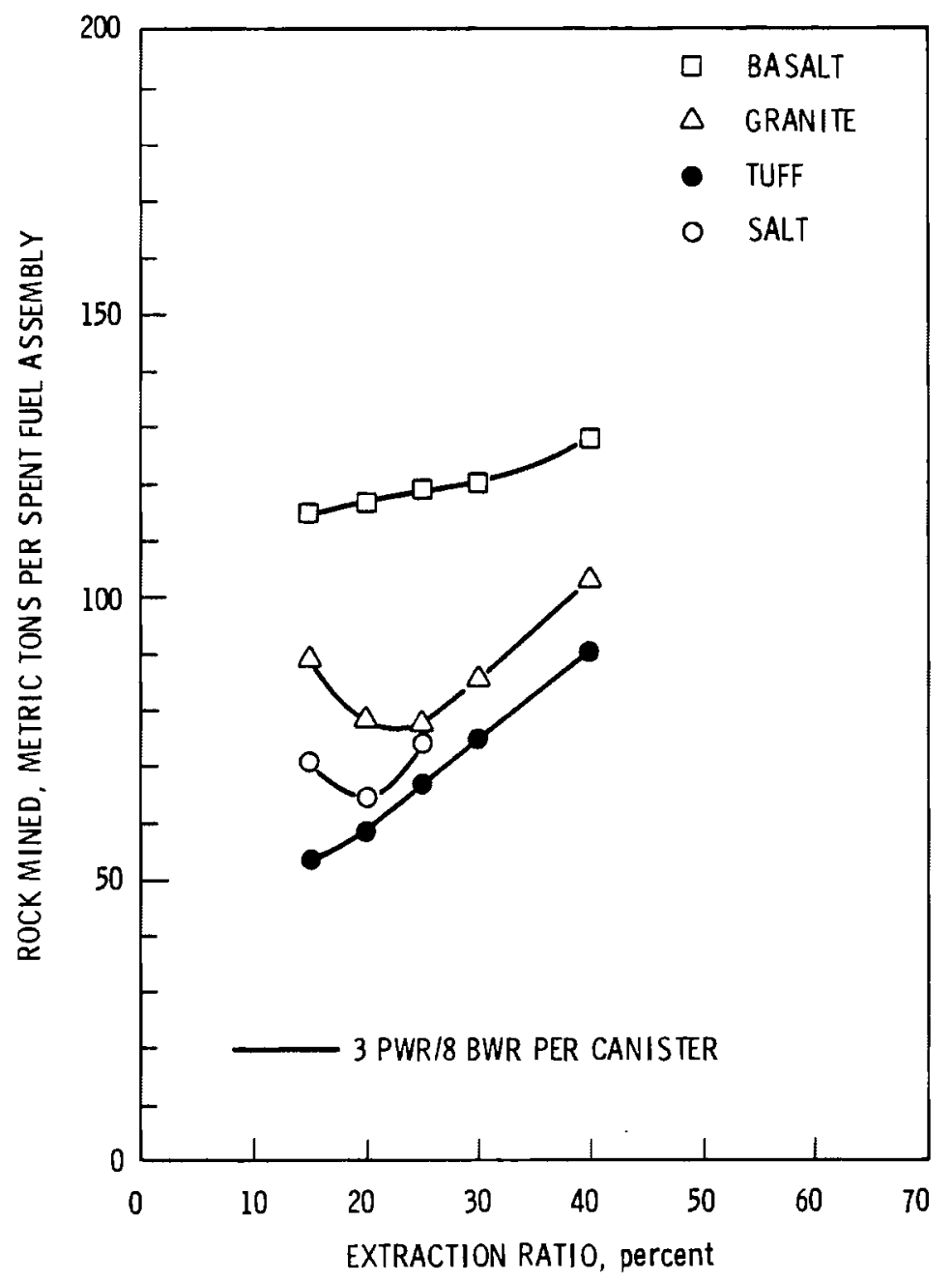

FIGURE 6.15. The Effect of Extraction Ratio on Total Rock Mined Using Four Rows Per Room

repositories, the amount of rock mined per spent fuel assembly decreases as the extraction ratio increases from 15 to $20 \%$. At $25 \%$ in salt and $30 \%$ in granite, the amount of rock mined per fuel assembly begins to increase sharply, corresponding to the sharp changes in the slopes in the spent fuel capacity curve in Figure 6.14. This same effect is postulated to also occur for tuff repositories at extraction ratios below 15\%. Because the number of spent fuel assemblies emplaced in the basalt repository increase rather steadily with increasing extraction ratio, as shown in Figure 6.14 , no minimums in rock mined per spent fuel assembly occur, as shown in Figure 6.15 . 
With an understanding of the nature of these trends, the behavior of the cost curves as a function of extraction ratio in Figure 6.13 can now more clearly be understood. As Figure 6.13 shows, when extraction ratios increase from 15 to $25 \%$, the number of assemblies emplaced increases sharply for salt and granite repositories. This increase results in lower fixed unit costs and in lower unit mining costs. However, at a $20 \%$ extraction ratio in salt and a $25 \%$ extraction ratio in granite, unit mining costs beg in to increase sharply and overcome the small cost decreases in fixed unit costs as slightly more assemblies are emplaced. This same effect occurs for the repositories in tuff at a $20 \%$ extraction ratio. For the basalt repository, the number of assemblies emplaced continues to increase substantially as extraction ratios are increased, and the decrease in fixed unit costs overshadows the increase in unit mining costs. This condition results in a minimum cost at an extraction ratio of $40 \%$.

In sumary, it appears that minimum repository costs will occur for different media at different extraction ratios, depending on the minimum pitch and the limiting thermal criteria. For repositories in which emplacement density is limited by very-near-field thermal criteria such as basalt, higher extraction ratios appear more optimum. Using four rows per room results in slightly lower costs than one or two rows per room.

Fina $11 y$, note that the cost curves as a function of extraction ratio in Figure 6.13 are a 11 fairly flat, indicating that constructing repositories at a less than optimum extraction ratio or fewer rows per room does not result in large cost penalities. 


\section{REFERENCES}

Bechtel National Inc. 1979a. National Waste Terminal Storage - Conceptual Reference Repository Description. ONWI/SUB/79/E512-01600.16, Prepared for the Office of Nuclear Waste Isolation by Battelle-Columbus Laboratories, Columbus, Ohio.

Bechtel National Inc. 1979b. An Assessment of LWR Spent Fuel Disposal Options. ONWI-39, Prepared for the Office of Nuclear Waste I solation by Battelle-Columbus Laboratories, Columbus, Ohio.

Brown, R. W. 1980. Standardized Repository and Encapsulation Facility Cost Est imates For Comparative Evaluation and Pricing Study. ONWI-110, Prepared for the Office of Nuclear Waste I solation by Battelle-Columbus Laboratories, Columbus, Ohio.

Department of Energy. 1978. Preliminary Estimates of the Charge for Spent Fuel Storage and Disposal Services. D0E/ET-0055, Department of Eneray, Wash ington, D.C.

Department of Energy. 1979. Technology for Commercial Radioactive Waste Management. DOE/ET-0028, Department of Energy, Washington, D.C.

Department of Energy. 1980a. Final Environmental Impact Statement Management of Commercially Generated Radioactive Waste. DOE/EIS-0046F, Department of Energy, Washington, D.C.

Department of Energy. 1980b. Statement of Position of the United Stated Department of Energy on the Storage and Disposal of Nuclear Waste. DOE/NE0007 , Department of Energy, Washington, D.C.

E. R. Johnson Associates Inc. 1981. Systems Impacts of Spent Fuel Disassembly Alternatives. JAI-173, E. R. Johnson Associate Inc., Reston, Virginia.

Einziger, R. E. et a 1. 1981. Zircaloy Ciadding--Tough Containment for Spent Fue 1 Storage. Presented at the 1981 Annual Meeting of American Nuclear Soc iety, June 7-12, Miami Beach, Florida.

Forster, J. D. 1979. The Economics of Mined Geologic Repositories. ONWI-93, Prepared for the Office of Nuclear Waste Isolation by Battelle-Columbus Laboratories, Columbus, Ohio.

Forster, J. D. and S. Cohen. 1980. The Discount Rate in the Spent Fuel Storage and Disposal Fee. ONWI-189, Prepared for the Office of Nuclear Waste Isolation by Battelle-Columbus Laboratories, Columbus, Ohio.

Interagency Review Group. 1979. Report to the President by the Interagency Review Group on Nuclear Waste Management. TID-29442, National Technical Information Service, Springfield, Virginia. 
Kaiser Engineers Inc. 1978a. A National Waste Terminal Storage Repository in a Bedded Salt Formation for Spent Unreprocessed Fuel. Kaiser Engineers Inc., Oakland, California.

Kaiser Engineers Inc. 1978b. Spent Fuel Receiving and Packaging Facility Conceptual Design Report. RHO-CD-506, Kaiser Engineers Inc., Oak land, California.

Kaiser Engineers Inc. 1980. Retrieval Options Study. ONWI-63, Prepared for the Office of Nuclear Waste Isolation by Battelle-Columbus Laboratories, Columbus, Ohio.

Parsons, Brinkerhoff, Quade and Douglas. 1978. Technical Support for GEIS: Radioactive Waste I solation in Geologic Formations. Y/OWI/TM-36, Prepared for and available from the U.S. Department of Energy, Washington D.C.

Stearns-Roger Engineering Company. 1978. A National Waste Terminal Storage Repository for Storing Reprocessing Wastes in a Dome Salt Formation. Stearns-Roger Engineering Company, Denver, Colorado.

Stearns-Roger Engineering Company - Kaiser Engineers. 1979. National Waste Terminal Storage Repositories 1 and 2 - Cost Estimate Reconciliation Study Volume I. ONWI-76, Available from the Office of Nuclear Waste Isolation, Batte11e-Columbus Laboratories, Columbus, Ohio.

Thadani, M. 1980. A Depth Optimization Study for Geologic Isolation of Radioactive Wastes. PNL-3079, Prepared by Teknekron Inc. for Pacific Northwest Laboratory, Richland, Washington.

Westinghouse Electric Corporation. 1981. Engineered Waste Package Conceptual Design - Spent Fuel Disposal in Salt. AESD-TME-3087, Westinghouse Electric Corporation, Pittsburgh, Pennsylvania. 
APPENDIX A

BASALT REPOSITORY COST ESTIMATE USING

BASALT WASTE ISOLATION PROJECT DATA 
APPENDIX A

BASALT REPOSITORY COST ESTIMATE US ING BASALT WASTE ISOLATION PROJECT DATA

A conceptual design study is currently being completed for a basalt repository to be located near Hanford, Washington. Because a conceptual cost estimate for this project, named the Basalt Waste Isolation Project (BWIP), is not yet available, a request was made to develop a preliminary cost estimate through the use of the RECON model. Kaiser Engineers and Parsons, Quade, Brinkerhoff and Douglas, who have combined in a joint venture to develop the conceptual repository design, have provided sufficient cost data to develop this preliminary cost estimate.

\section{A.1 BWIP DESIGN BASIS ANALYSIS}

The BWIP repository employs a rectangular design with two large panel areas divided by main pillars, in which the shafts are located. This design differs significantly from the CRRD design in that the rooms are placed at right angles to the main corridors. The package design consists of disassembled fuel elements from three PWR or seven BWR fuel assemblies packaged in a carbon steel canister with a titanium skin. The prepackaged fuel is assumed to be received at the repository where it is overpacked before being emplaced. Emplacement is in $1.1 \mathrm{~m}$ diameter holes drilled in the floor of the room. A ceramic liner surrounded by crushed basalt and bentonite is emplaced in the hole prior to package emplacement. The design assumes that 1750 packages per year will be emplaced.

The repository has a total area of $\sim 1880$ acres with an effective emplacement area of slightly more than 1200 acres. After operations end, the repository is assumed to be backfilled using a 50\% mixture of bentonite pellets and crushed basalt. The repository has five shafts for men and materials, basalt handling and mine exhaust, waste handling, confinement air intake, and confinement air exhaust. The capacity of the repository is $\sim 35,000$ spent fuel packages and 32,000 low-level waste drums. The design assumes that all packages 
are emplaced at a distance of $3.6 \mathrm{~m}$. Repository design life is for a 20-year operating and waste emplacement period and a 25 -year retrieval period. The repository air intake is refrigerated prior to being sent down into the repository.

\section{A.2 RESULTS}

Based on data fumished by the Rockwell Hanford operations and the joint venture mentioned above, the RECON model calculated the following repository characteristics:

- total repository capacity, 235,000 canisters

- total rooms excavated, 126

- number of packages per row, 292

- tota 1 rock mined, 16.3 million tons

- minimum pitch between canisters, 3.67 meters

- average near-field thermal loading, 47.3 kilowatts per acre

- average far-field thermal loading, 30.3 kilowatts per acre.

The total cost sumary for the BWIP repository is listed in Table A.1, using the category definitions defined in Section 5.3. Total construction costs are estimated at $\$ 585$ million for surface facilities, shafts, and preoperational mining. Total repository costs are $\sim \$ 4.8$ billion. Unit costs shown at the bottom of the table are $\sim \$ 99 / \mathrm{kg}$ in 1981 dollars. An examination of the unit cost analysis shows that most of the costs are attributable to the packaging and other components (which include the backfilling costs). Other significant contributions to cost come from hole drilling, materials, labor and construction. The mining and shaft costs only account for $\sim 10 \%$ of the total. A comparison of the cost estimates for the basalt waste isolation program repository and the generic basalt repository evaluated in this study was made and is shown in Figure A.1. The generic basalt cost estimate is slightly higher than the BWIP cost estimates. An examination of the cost data reveals the following reasons for these differences: 
TABLE A.1. Cost Sumary for BWIP Repository

\begin{tabular}{|c|c|}
\hline Operating Costs for Waste & $\begin{array}{l}\text { Costs, Millions } \\
\text { of } 1981 \text { Dollars } \\
\end{array}$ \\
\hline \multicolumn{2}{|l|}{ Construction Costs For: } \\
\hline $\begin{array}{l}\text { Surface Facilities and } \\
\text { Equipment }\end{array}$ & 402 \\
\hline Shafts & 132 \\
\hline Preoperational Mining & 51 \\
\hline Construction Subtotal & 585 \\
\hline $\begin{array}{l}\text { Operating Costs for Waste } \\
\text { Hand ling and General } \\
\text { Operations Support }\end{array}$ & 1722 \\
\hline Mining Operating Costs & 445 \\
\hline $\begin{array}{l}\text { Underground Operating } \\
\text { Costs }\end{array}$ & 600 \\
\hline Utility Costs & 73 \\
\hline Preproduction Costs & 102 \\
\hline $\begin{array}{l}\text { Decommissioning and } \\
\text { Sealing Costs }\end{array}$ & 111 \\
\hline Cont ingenc ies & $\underline{1173}$ \\
\hline TOTAL & 4811 \\
\hline Unit Costs For: & $\$ / \mathrm{Kg} \mathrm{HM}$ \\
\hline Construction & 12.50 \\
\hline Shafts & 3.70 \\
\hline Mining & 6.70 \\
\hline Labor & 16.00 \\
\hline
\end{tabular}


TABLE A.1. (contd)

\begin{tabular}{lc} 
Operating Costs for Waste & $\begin{array}{c}\text { Costs, Millions } \\
\text { of 1981 Dollars }\end{array}$ \\
\cline { 2 - 2 } Packaging & 24.00 \\
Hole Drilling and & \\
Materials & 12.50 \\
Other & $\underline{23.40}$ \\
TOTAL & 98.80
\end{tabular}

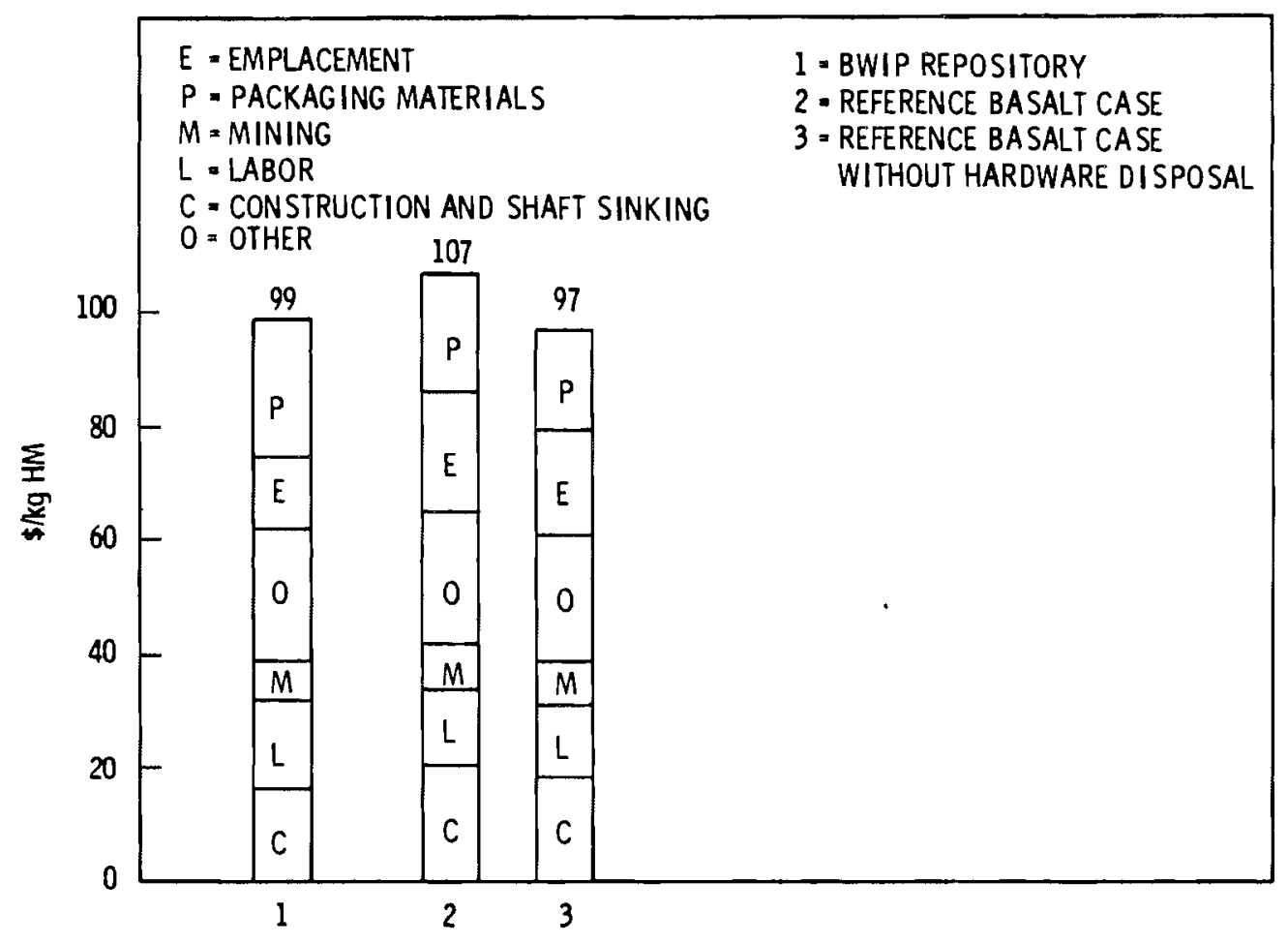

FIGURE A.1. A Comparison of BWIP Repository Costs Versus the Reference Basalt Case in this Study

- Capital costs for the BWIP design are significantly lower due to lower receiving and packaging facility costs. Less receiving capacity is required at the BWIP repository because the packages are assumed to be prepackaged before arriving. Thus, 1750 packages 
would be handled per year at the BWIP repository, as opposed to a maximum of 15,000 assemblies hand led per year at the generic repository.

- The BWIP design also is less costiy because expensive spent fuel storage pools are not needed at the repository to store the fuel until it is packaged. Partially offsetting these cost differences is the assumption in the BWIP estimate of an extra $\$ 10,000$ per package for packaging costs.

- Because the fue 1 received at the BWIP repository is prepackaged, provisions for storage and disposal of the endfittings and hardware generated by disassembling the spent fuel is not included in the BWIP design.

- The hole drilling cost estimates provided by Kaiser were $\$ 6500$ per hole or approximately half of the hole drilling costs estimated for the generic repository.

Figure A.1 shows the effect on costs if the additional cost due to storage and disposal of the hardware is subtracted from the generic repository cost estimate. This results in a cost reduction of $\sim \$ 10 / \mathrm{kg} \mathrm{HM}$, giving a tota 1 repository cost without hardware of $\$ 97 / \mathrm{kg} H M$ or slightly below the BWIP estimate.

Since actual conceptual design cost estimates were not available for the BWIP repository, a benchmark could not be made with this repository. However, a comparison of the cost results using the BWIP assumptions and generic repository assumptions shows that no apparent bias exists against basalt repositories using the reference case assumptions. 


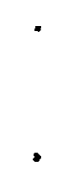

$\downarrow$

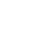


No. of

Copies

\section{OFFSITE}

A. A. Churm DOE Chicago Patent Group 9800 South Cass Avenue

Argonne, IL 60439

25 D. G. Dippold

Office of Nuclear Waste Isolation

505 King Avenue

Columbus, $\mathrm{OH} 43201$

27 Technical Information Center P.0. Box 62

Oak Ridge, TN 37830

\section{ONSITE}

3 DOE Richland Operations Office

H. E. Ransom

J. J. Schreiber (2)
No. of

Copies

44 Pacific Northwest Laboratory

A. J. Boege 1

J. B. Burnham

L. L. Clark (21)

M. 0. Cloninger

B. M. Cole

D. E. Deonigi

D. A. Dingee

R. L. Enge 1

R. M. Fle ischman

C. M. Heeb

G. M. Holter

J. H. Jarrett

R. W. McKee

E. T. Merrill

R. I. Smith

M. K. White

L. D. Williams

Technical Information (5)

Publishing Coordination (2) 
